\title{
Future Hydrological Drought Analysis Considering Agricultural Water Withdrawal Under SSP Scenarios
}

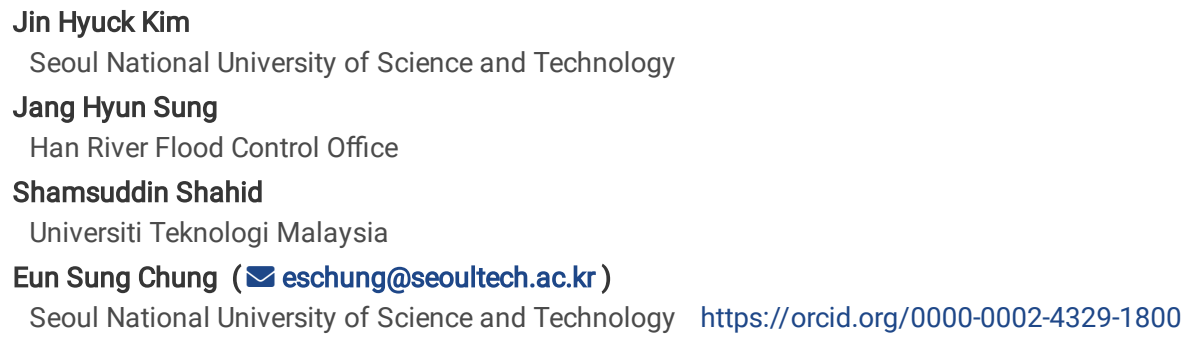

\section{Research Article}

Keywords: Agricultural water withdrawal, CMIP6, Shared socioeconomic pathways, Standardized Runoff Index, Deep Belief Network, Reliability ensemble average

Posted Date: January 31st, 2022

DOI: https://doi.org/10.21203/rs.3.rs-1291959/v1

License: () (i) This work is licensed under a Creative Commons Attribution 4.0 International License. Read Full License

Version of Record: A version of this preprint was published at Water Resources Management on March 24th, 2022. See the published version at https://doi.org/10.1007/s11269-022-03116-1. 


\section{Abstract}

Hydrological drought is assessed through river flow, which depends on river runoff and water withdrawal. This study proposed a framework to project future hydrological droughts considering agricultural water withdrawal (AWW) for shared socioeconomic pathway (SSP) scenarios. The relationship between AWW and potential evapotranspiration (PET) was determined using a deep belief network (DBN) model and then applied to estimate future AWW using projections of the twelve global climate models (GCMs). 12 GCMs were bias-corrected using the quantile mapping method, climate variables were generated, and river flow was estimated using the soil and water assessment tool (SWAT) model. The standardized runoff index (SRI) was used to project the changes in hydrological drought characteristics. The results revealed a higher occurrence of severe droughts in the future. Droughts would be more frequent in the near future (2021-2060) than in the far future (2061-2100) and more severe when AWW is considered. Droughts would also be more severe for SSP5-8.5 than for SSP2-4.5. The study revealed that the increased PET due to rising temperatures is the primary cause of the increased drought frequency and severity. The AWW will accelerate the drought severities in the future in the Yeongsan River basin.

\section{Introduction}

Droughts are classified into meteorological, hydrological, agricultural, and socioeconomic droughts according to the lack of precipitation, runoff, and soil moisture (Heim et al., 2002). Drought is a complex natural process that starts with a lack of precipitation and leads to a lack of soil moisture due to reduced river flow, which adversely affects plant and crop growth and human life (Li et al., 2013). Hydrological drought plays an important role in water resource management and planning for population and crop growth (Van Loon et al., 2011). The hydrological drought is a natural disaster defined as a lack of water resources in a region (Beran et al., 1985), which occurs due to the interaction of climate and water cycle processes in a watershed (Tate et al., 2000). Multiple sectors, such as agricultural activity, urban water sources, industry, depend primarily on surface water resources (Vasiliades et al., 2011). Thus, hydrological droughts can directly impact multiple stakeholders, such as those being involved in power generation, irrigation, and recreational pursuits within the affected basin (Konapala et al., 2020; Jiang et al., 2019).

Drought indices are generally used to assess drought conditions in an area and examine the various characteristics of drought, including its severity, duration, and spatial expanse (Mishra et al., 2010; Sung and Chung, 2014). Many drought indices have been proposed, including the Standardized Precipitation Index (SPI), the Streamflow Drought Index (SDI), the Standardized Precipitation Evapotranspiration Index (SPEI), the Palmer Drought Severity Index (PDSI), and the Standardized Runoff Index (SRI). In addition, the SPI, SPEI and SRI among different drought indices are suitable for the characteristics of droughts at various time scales (Kebede et al., 2020). Many studies have attempted to predict future droughts using a drought index. Lin et al. (2020) analyzed future droughts of the upper Huai River basin in China for CMIP5 scenarios using the SPI. Li et al. (2020) analyzed droughts in China using two meteorological drought indices, the SPI and SPEI. Javadinejad et al. (2021) analyzed droughts in California in the USA for the CMIP5 RCP 8.5 scenario using the PDSI, an agricultural drought index. The SDI and SRI have been used for hydrological drought analysis. The SRI (Shukla and Wood, 2008) determined the hydrological drought of an area from river flow observation. The SRI has been used extensively for monitoring hydrological droughts due to its simplicity in computation, relatively low data requirements, and comparability at various time scales (Jehanzaib et al., 2020).

Global climate models (GCMs) are popularly used for future drought analysis to obtain projections of climate variables, such as precipitation levels, temperatures, and wind speeds (Tan et al., 2017). GCMs project future climates based on several defined scenarios. The latest projections of GCMs are made based on new scenarios that include climate change mitigation and adaptation efforts and future social and economic changes, such as population, economic development, ecosystems, resources, institutions, and social factors (O'Neill et al., 2016). Several studies have been conducted for future drought analysis using newly developed SSPs worldwide (Shrestha et al., 2020; Su et al., 2021; Zhai et al., 2020; Mondal et al., 2021). The results showed different drought characteristics relative to those obtained for the RCPs (Kim et al., 2021).

Hydrological drought is usually calculated based on natural river flow data (Jiao et al., 2020; Sutanto et al., 2020). The river flow depends not only on natural flow due to rainfall but also on river water withdrawal. Therefore, the river flows considering water withdrawal should be used in SRI calculations. However, in most studies, river flow projections using GCMs do not include future river water withdrawal. Accurate estimation of agricultural water use is always challenging because observational data are not abundant, and usage amounts are not constant. Methods assessed thus far include simulations (Saddique, 2020; Naderi et al., 2021) and monitoring (Mdemu et al., 2020; Pratihar et al., 2020). Recently, some studies have sought to estimate agricultural water use using artificial intelligence techniques based on monitoring data (Sung et al., 2021).

Climate change creates uncertainty about water resources (Abbaspour et al., 2015). GCMs used for climate projections are associated with uncertainties. Data targeted for future water resource planning should consider the uncertainty of future climate change scenarios (Höllermann and Evers 2017). For this, past studies adopted different techniques, namely, reliability ensemble averaging (Giorgi and Mearns 2003), Bayesian analysis (Das and Umamahesh 2018), fuzzy uncertainty analysis (Najafi and Hessami Kermani 2017), imprecise probability (Ghosh and Mujumdar 2009), and Monte Carlo simulation (Shackley et al. 1998) to assess the uncertainty in the climate change studies.

This study proposed a framework for future hydrological drought projections considering agricultural water withdrawal (AWW) for different shared socioeconomic pathways (SSPs). The study used the concept proposed by Sung et al. (2020) to generate future agricultural water withdrawal (FAWW) amount using a deep belief network (DBN). Subsequently, the model was applied to project future AWW levels from the PET estimated for the twelve GCMs for two scenarios, SSP2-4.5 and 5-8.5. The soil and water assessment tool (SWAT) was used to simulate river runoff, and the SRIs with and without AWW were compared for two future periods (2021-2060 and 2061-2100). Finally, the uncertainty in future hydrologic droughts was analyzed.

\section{Methodology}




\subsection{Procedure}

This study consists of a total of six steps. The first step was to perform bias correction of the simulations of the twelve GCMs using the quantile mapping method. The performance of bias correction was evaluated using several statistical performance indices. The second step was to formulate the SWAT model for the Yeongsan River basin using historical meteorological observation data, AWW, and discharges from the wastewater treatment facility. The SWAT parameters were calibrated using SWAT-CUP (Calibration and Uncertainty Procedure; Abbaspour et al., 2007) based on observed runoff levels at Geukrakgyo (bridge), as shown in Figure 1. The third step was to estimate the future AWW outcomes using GCMs based on the derived relationship between PET and AWW for the observation period. The PET was calculated using Thornthwaite's (1948) method, and the relationship was quantified using the DBN. The fourth step estimated the river flow for the twelve GCMs and two SSP scenarios. The fifth step calculated the SRI and analyzed the future drought characteristics. The analysis of the future period was divided into the near future (NF) (2021-2060) and the far future (FF) (2061-2100). In the last, uncertainty analysis was performed using REA (Reliability ensemble average) for the runoff and drought index considering with or without AWW.

\subsection{Study area and datasets}

The basin area of the Yeongsan River is $3,371.4 \mathrm{~km}^{2}$, and the average annual temperature and rainfall amount are $14.0^{\circ} \mathrm{C}$ and $1,293 \mathrm{~mm}$, respectively. Land use includes forest (45.4\%), agriculture (35.5\%), urban areas (7.3\%), grasslands (5.2\%), water bodies (3.4\%), bare lands (1.8\%), and wetlands (1.4\%). The Yeongsan River basin, located in the southwestern region of Korea, is known as a large-scale agricultural area, even after industrialization. The most common major crop in the Yeongsan River basin is rice, though pears, onions, and garlic are also grown. The Yeongsan River often lacks sufficient river flow during the dry season.

This study used the geographical, climatic, and hydrological data obtained from the Korea meteorological administration, the Water Resource Management Information System (WAMIS), the Environmental Geographic Information Service (EGIS), and the Yeongsan River Flood Control Office. As shown in Figure 1, the Yeongsan River basin consists of 21 sub-basins which are divided based on the digital elevation model (DEM). Data from six meteorological stations near or in the Yeongsan River Basin and one water-level station in the Yeongsan River Basin were used in this study.

\subsection{GCMs and shared socioeconomic pathway}

The GCM includes physical processes in the atmosphere, oceans, glaciers, and the surface, making it useful for analyzing climate change and estimating the future climate due to increasing concentrations of greenhouse gases. GCMs provide climate information at a grid spacing distance of a minimum of $125 \mathrm{~km}$ and a maximum distance of $400 \mathrm{~km}$. IPCC developed new climate scenarios for Assessment Report 6 (AR6), which consider social and economic factors together. New SSP scenarios are defined taking into account various land use and greenhouse gas emission conditions. Therefore, compared to the existing RCP scenario, the SSP scenario is being upgraded or improved. This study used 12 CMIP6 GCMs, described in Table 1, for SSP2-4.5 and SSP5-8.5.

Table 1

Information of the GCMs used in this study

\begin{tabular}{|c|c|c|}
\hline Modeling Center & Models & $\begin{array}{l}\text { Resolution } \\
\text { (Longitude x Latitude) }\end{array}$ \\
\hline Center for Australian Weather and Climate Research (CAWCR) & ACCESS ESM 1-5 & $1.25^{\circ} \times 1.875^{\circ}$ \\
\hline Canadian Earth System Model version 5, Canadian Centre for Climate Modelling and Analysis (Canada) & CanESM5 & $2.81^{\circ} \times 2.81^{\circ}$ \\
\hline \multirow[t]{2}{*}{ Institute for Numerical Mathematics, Russian Academy of Science, (Russia) } & INM-CM4-8 & $2^{\circ} \times 1.5^{\circ}$ \\
\hline & INM-CM5-0 & $2^{\circ} \times 1.5^{\circ}$ \\
\hline Institut Pierre Simon Laplace & IPSL-CM6A-LR & $1.26^{\circ} \times 2.5^{\circ}$ \\
\hline NASA Goddard institute for Space Studies & KIOST-ESM & $2^{\circ} \times 2.5^{\circ}$ \\
\hline Atmosphere and Ocean Research Institute, The University of Tokyo & MIROC6 & $1.4^{\circ} \times 1.4^{\circ}$ \\
\hline \multirow[t]{2}{*}{ Max Planck Institute for Meteorology (MPI-M) (Germany) } & MPI-ESM1-2-HR & $0.94^{\circ} \times 0.94^{\circ}$ \\
\hline & MPI-ESM1-2-LR & $1.9^{\circ} \times 1.9^{\circ}$ \\
\hline Meteorological Research Institute (Japan) & MRI-ESM2-0 & $1.1^{\circ} \times 1.1^{\circ}$ \\
\hline \multirow[t]{2}{*}{ Norwegian Climate Centre (Norway) } & NorESM2-LM & $2.50^{\circ} \times 1.89^{\circ}$ \\
\hline & NorESM2-MM & $0.94^{\circ} \times 1.25^{\circ}$ \\
\hline
\end{tabular}


Table 2

Description of deep learning model parameter settings

\begin{tabular}{|ll|}
\hline Items & Detail \\
\hline Prediction variable & agricultural water withdrawal (AWW) \\
\hline Input variable & $\begin{array}{l}\text { 1-month cumulative PET (PET) } \\
\text { Monthly agricultural water withdrawal (DAWW) }\end{array}$ \\
\hline Training parameters & $\begin{array}{l}\text { Number of hidden units: } 10,20,30 \\
\text { Learning rate: } 0.1,0.5,0.9 \\
\end{array}$ \\
& Number of epochs: $100,500,1000$ \\
& Batch size: $6,12,24$ \\
\hline
\end{tabular}

\subsection{Quantile mapping method}

GCM simulations are prone to bias; therefore, differences between GCM historical simulations and actual observations always exist. Many methods have been used for the bias correction of GCM data (Song et al., 2020). Quantile mapping is an effective representative method to correct the difference between the GCM simulated and observed values (Dosio et al., 2011; Gudmundsson et al., 2012). As shown in Eq. 1, the quantile mapping method transforms a model variable $\left(P_{m}\right)$ using the integral probability transformation function in such a way that the newly constructed distribution becomes equal to the distribution of the observed variable $\left(P_{0}\right)$.

$$
P_{0}=h\left(P_{m}\right)
$$

1

where $P_{0}$ is the observed precipitation, $P_{m}$ is the GCM precipitation, and $h$ is the transformation function. Based on this, the observed precipitation is calculated as the inverse function of the cumulative distribution function (CDF), as expressed in Eq. 2,

$$
P_{0}=F_{0}^{-1}\left(F_{m}\left(P_{m}\right)\right)
$$

2

where $F_{m}$ is the CDF of $P_{m}$ and $F_{0}{ }^{-1}$ is the inverse function of the CDF of $P_{0}$.

This study used a non-parametric smoothing spline method as a transformation function, found to be more reliable for correcting daily precipitation and temperature data in South Korea in a previous study (Song et al. 2021).

\subsection{SWAT and SWAT-CUP}

The SWAT can simulate changes in runoff, sedimentation, and nutrients in the watershed due to alterations in land use, soil types, and land management conditions (Arnold et al., 1998). The SWAT model was used in this study to estimate flows under future climate change scenarios.

There are two methods for parameter optimization of SWAT models: manual calibration and automatic calibration. The SWAT model basically provides a manual calibration function, but the calibration result may vary depending on the user's know-how and skill level. SWAT-CUP was developed to perform automatic calibration of SWAT parameters. Parametric optimization of the SWAT model can simulate runoff from a wide range of large-scale watersheds using observational data. It can predict changes in hydrological parameters under different management practices and physical environmental factors (Daloğlu et al., 2014; Gassman et al., 2007). This study used the SUFI2 algorithm, an optimization technique that quantifies and expresses the uncertainty of parameters via the multivariate uniform distribution (Arnold et al., 1998).

\subsection{Standardized runoff index}

SPI, proposed by McKee et al. (1993), involves fitting a gamma probability density function (PDF) to precipitation at a station scale. The $\alpha$ and $\beta$ parameters of the gamma distribution are estimated for each timescale of interest (i.e., 1, 3, 6, and 12 months). The gamma distribution is defined by its pdf of $x$ as follows:

$$
g(x, \alpha, \beta)=\frac{1}{\beta^{\alpha} \tau(\alpha)} x^{\alpha-1} e^{-\frac{x}{\beta}}, x \geq 0
$$

3

where $\alpha$ and $\beta$ are shape and scale parameters, respectively; $x$ is the cumulative monthly precipitation; and $\tau(\alpha)$ is the gamma function. Maximum likelihood solutions are used to estimate $\alpha$ and $\beta$ (Thom, 1958). The parameters are then used to find the cumulative probability of observed precipitation in a given 
month and timescale. The cumulative probability, after its computation, is transformed into the standard normal random variable $z$ with a mean equal to 0 and a standard deviation of 1 , which is the value of the SPI.

McKee et al. (1993) selected the gamma distribution for fitting monthly precipitation data series, suggesting that this procedure can be applied to other variables relevant to drought (streamflow or reservoir contents). An analysis by Shukla and Wood (2008) found that the degree of suitability can vary depending on the characteristics of the runoff variables. They also showed that the gamma distribution performed better in a drought analysis for low runoff. This study performed a drought analysis using a gamma distribution for the runoff.

The SRI (Shukla and Wood, 2008) was developed to assess hydrological droughts considering runoff data based on the SPI methodology. SRI is an index that can be calculated similarly to SPI using only runoff data. Like SPI, SRI can calculate drought indices on a daily or monthly scale using observed and predicted runoff data. A hydrological drought defined by SRI is extreme if this value is less than -2 , severe if it is less than -1.5 , moderate if it is less than - 1 , and mild if it is less than 0 . An SRI of more than 0 indicates no drought.

\subsection{Reliability ensemble average}

REA (Reliability ensemble average), developed by Giorgi and Mearns (2002), can evaluate the similarity between GCM outputs and observed data for historical periods and consider the differences in GCM projection for future periods. Therefore, it quantifies the reliability by considering both historical and projected data, as shown in Eq. 4

$$
w_{i}=\left[\left(w_{B, i}\right)^{m} \times\left(w_{D, i}\right)^{n}\right]^{\left[\left(\frac{1}{(m \times n)}\right)\right]}=\left\{\left[\frac{\epsilon}{a b s\left(B_{i}\right)}\right]^{m}\left[\frac{\epsilon}{a b s\left(D_{i}\right)}\right]^{n}\right\}^{\left[\frac{1}{(m \times n)}\right]}
$$

4

where, $w_{i}$ is the weight of the GCM simulation and $w_{B, i}$ is an error term between the GCM simulations and observations in the historical period. In addition, $W_{D, i}$ represents the difference between the GCM projection and the historical period. In this process, the initial value of $w_{D, i}$ is calculated as

$\left[D_{i}=\left(\triangle G C M_{i}-\triangle G C M\right)\right]$, where GCM is the difference between the averages of GCM for the historical period and the observed data, $\epsilon$ is the difference between the maximum and minimum values of the moving average, $m$ and $n$ are the weight for the error and the difference term, respectively

\section{Result}

\subsection{Bias correction for GCMs}

The performances of the bias-corrected precipitation and temperatures of the twelve GCMs are shown in Figure 2. The results show an improvement in the precipitation and temperature of GCMs after bias correction. The coefficient of determination $\left(R^{2}\right)$ of the GCMs increased from 0.04 to 0.99 for precipitation. The root mean square error (RMSE) of GCM precipitation decreased from 16.29 to 1.93. The standard deviation (SD) of the bias-corrected GCMs also becomes closer to the SD of the observed precipitation. In the case of temperature, the $\mathrm{R}^{2}$ of the GCMs increased from 0.88 to 1.00 , and the RMSE decreased from 4.64 to 0.05 . The SDs of the bias-corrected GCMs become close to the observed SD.

The RMSE of MPI-ESM1-2-LR precipitation showed the best performance of 15.33, and IPSL-CM6A-LR showed the lowest performance of 17.95 before correction. After correction, MRI-ESM2-0 showed the best performance of 0.5, and INM-CM4-8 showed the lowest performance of RMSE 5.16. For SD, IPSLCM6A-LR showed the best performance of 12.29, and KIOST-ESM showed the lowest performance of 6.99 before correction. After correction, all GCMs showed SD near to observed SD. In the case of $\mathrm{R}^{2}$, all GCMs showed low performance 0-0.1 before correction, but the performance exceeded 0.9 after correction.

In the case of temperature, MIROC6 showed the lowest RMSE of 3.87, and KIOST-ESM the highest of 6.95 before correction. After correction, all GCMs showed RMSE 0.06 or less. For SD, IPSL-CM6A-LR showed the best performance of 11.58, and KIOST-ESM showed the lowest performance of 5.15 before correction. After correction, all GCMs showed SD more than 9.40 or near to observed SD. All GCMs before correction showed $\mathrm{R}^{2}$ of around 0.75 before bias correction, while after correction, they showed $\mathrm{R}^{2} 0.9$ or more.

\subsection{SWAT formulation}

After considering AWW in the Yeongsan River basin, SWAT parameters were optimized using the SUFI2 algorithm. SWAT parameters related to groundwater levels, HRU, watersheds, soil, and channel routing affect the runoff process. The NSE was used as an objective function in SUFI2 for optimizing the SWAT parameters. Several studies (Schuol et al., 2006; Yang et al., 2008; Andersson et al., 2009) recommended 500 to 1500 repetitions to optimize SWAT parameters using SUFI2. This study selected 1000 repetitions.

The optimized values of the SWAT parameters are shown in Table 3. Figure 3 shows the calibration result at Geukrakgyo station for 2008-2009. The result showed that $\mathrm{R}^{2}$ increased from 0.75 to 0.92 , and NSE increased from 0.53 to 0.84 . For the validation period, $\mathrm{R}^{2}$ was 0.90 , and NSE was 0.80 . The results revealed that the SWAT model was calibrated well for river runoff prediction. 
Table 3

SWAT input parameters and their ranges selected for calibration

\begin{tabular}{|llll}
\hline Input $\quad$ Parameter & Description & Range & Min \\
\cline { 3 - 4 }
\end{tabular}

\begin{tabular}{|c|c|c|c|c|c|}
\hline \multirow{6}{*}{$\begin{array}{l}\text { Ground } \\
\text { water }\end{array}$} & ALPHA_BF & Baseflow alpha factor & 0 & 1 & 1 \\
\hline & GW_DELAY & Groundwater delay time & 0 & 500 & 125 \\
\hline & GW_REVAP & Groundwater re-evaporation coefficient & 0.02 & 0.2 & 0.16 \\
\hline & GWQMN & Threshold water level in shallow aquifer for baseflow & 0 & 5000 & 2076 \\
\hline & RCHRG_DP & Deep aquifer percolation fraction & 0 & 1 & 0.75 \\
\hline & REVAPMN & Threshold depth of water in the shallow aquifer for re-evaporation & 0 & 500 & 172 \\
\hline \multirow{2}{*}{$\begin{array}{l}\text { Hydrologic } \\
\text { response } \\
\text { unit }\end{array}$} & ESCO & Soil evaporation compensation factor & 0 & 1 & 0.27 \\
\hline & SLSUBBSN & Average slope length & 10 & 150 & 92.6 \\
\hline \multirow[t]{3}{*}{ Basin } & SFTMP & Snowfall temperature & -20 & 20 & -1.14 \\
\hline & SMFMX & Melt factor for snow on June 21 & 0 & 20 & 18.83 \\
\hline & SMTMP & Snow melt base temperature & -20 & 20 & 7.43 \\
\hline \multirow[t]{2}{*}{ Soil } & SOL_AWC & Available water capacity of the soil layer & 0 & 1 & 1 \\
\hline & SOL_K & Saturated hydraulic conductivity & 0 & 2000 & 714 \\
\hline \multirow{2}{*}{$\begin{array}{l}\text { Channel } \\
\text { routing }\end{array}$} & CH_K2 & Effective hydraulic conductivity in main channel alluvium & -0.01 & 500 & 58.19 \\
\hline & CH_N2 & Manning's " $n$ " value for the main channel & -0.01 & 0.4 & 0.34 \\
\hline Management & $\mathrm{CN} 2$ & 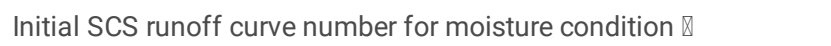 & 35 & 98 & 57.17 \\
\hline
\end{tabular}

\subsection{Estimation of future AWW}

The monthly PET for 2011-2019 starts to increase in April and reaches its maximum in July and August, accounting for $55 \%$ (310.4 mm) of the annual total PET (787.8 mm) (Fig. 4a). AWW reflects the annual cycle of agricultural activity; it starts to increase in May and reaches its maximum in September (Fig. 4b). The annual average AWW was $26.7 \%$, and it reached $63.2 \%$ in June. The highest AWW reflects the extreme drought that occurred in 2015.

Sung et al. (2020) proposed a DBN model to estimate the AWWs from the monthly PETs. This study employed the proposed DBN model. The RMSE, NSE and $\mathrm{R}^{2}$ of the model in the present study were found $0.14,0.87$, and 0.97 , respectively, confirming good performance. The DBN model was then used to estimate future AWW from the projected PETs estimated for the SSP scenarios (Figure 5.). The future AWW shows the annual cycle of Korean agricultural activity from May to September. For SSP 2-4.5, AWW in NF during the farming season increased by an average of $2.6 \%$ compared to the reference period. The largest increase was $4.2 \%$ in July. ACCESS ESM $1-5$ is the only GCM that showed a decrease in AWW by an average of $6.8 \%$ compared to the reference period.

Similarly, AWW in FF showed an increase by an average of 3.2\% compared to the past. The largest increase was $4.8 \%$ in July. ACCESS ESM $1-5$ was the only GCM that showed a decrease in AWW by an average of $6.1 \%$. During the non-farming season, AWW was projected to increase on average $2.6 \%$ in NF and $2.8 \%$ in FF. The future AWW was projected to decrease only in April on average $4.6 \%$ in NF and $3.8 \%$ in FF.

For SSP 5-8.5, AWW in NF during the farming season increased by an average of 3.6\% compared to the past. The largest increase was $5.1 \%$ in July. NorESM2LM projected the highest increase in AWW with an average of $4.5 \%$, and KIOST-ESM the least by $1.8 \%$. AWW in FF was projected to increase by an average of $4.4 \%$ than the reference period. The largest increase was $5.9 \%$ in July. Like in NF, NorESM2-LM showed the highest increase in AWW with an average of $5.3 \%$, and KIOST-ESM the least by $3.2 \%$. During the non-farming season, AWW was projected to increase by $2.7 \%$ in NF and $3.1 \%$ in FF. The AWW was also projected to decrease in April, like SSP2-4.5.

The future AWW was estimated to be higher for SSP5-8.5 than SSP2-4.5 and larger in the FF than in the NF. In addition, it was projected to increase higher in the farming season than in the non-farming. The highest increase was projected in the summer month of July. The increase in AWW mainly resulted from the global-warming-induced increase in the average monthly temperature.

\subsection{Estimation of climate variables and runoff}

\subsection{1 estimation of climate variables}

Variations in future precipitation and temperature are shown in Figure 6 . The future precipitation in NF was projected to increase by an average of $12.7 \%$ compared to the past for SSP2-4.5. Precipitation in spring and winter was projected to increase most, $93.5 \%$ and $67.3 \%$, respectively, while it was projected to 
decrease in summer and fall by $12.9 \%$ and $17.8 \%$, respectively. The future temperature in NF showed an average increase of $1^{\circ} \mathrm{C}$ compared to the past. The highest increase was projected in winter by $2.2^{\circ} \mathrm{C}$.

The future precipitation in FF was projected to increase by an average of $17.6 \%$. It followed the same trend as NF. The highest increases of $102.9 \%$ in spring, and $79.1 \%$ in winter and the largest decrease of $9.4 \%$ in summer and $16.5 \%$ in fall. The annual average temperature was projected to increase by $2.2^{\circ} \mathrm{C}$ in $\mathrm{FF}$, with the highest increase of $3.3^{\circ} \mathrm{C}$ in winter.

\subsubsection{River flow projections}

The projected changes in runoff for different SSPs are presented in Figure 7. For SSP2-4.5, the annual average flow in NF was projected to increase by $37.2 \%$. The flow in spring would increase the most by $213.3 \%$ and decrease the most in fall by $13.9 \%$. INM-CM5-0 showed the largest increase by an average annual flow of $57.7 \%$, while CanESM 5 showed the lowest increase of $20.1 \%$. The average annual flow in FF showed an increase by $45.1 \%$ compared to the reference period. The flow changes for each season were noticed similarly to NF. It was projected to increase by $238.5 \%$ in spring, $24.8 \%$ in summer, and $100.3 \%$ in winter and a decrease by $11.5 \%$ in fall. NorESM2-LM projected the largest increase in annual average flow by $70.7 \%$, and CanESM5 projected the lowest increase by $33.3 \%$.

The results for SSP5-8.5 were similar to those obtained for SSP2-4.5. However, the ranges of increase and decrease were larger. The annual average flow in NF was projected to increase by $32.1 \%$, with an increase of $200.1 \%$ in spring, $16.1 \%$ in summer and $69.9 \%$ in winter and a decrease of $17.1 \%$ in fall. IPSL-CM6A-LR showed the largest increase of $50.7 \%$, and CanESM5 showed the smallest of $10.9 \%$. The average annual flow in FF showed an average increase of $50.8 \%$. IPSL-CM6A-LR showed the largest increase of $76.9 \%$, while ACCESS ESM 1-5 showed the least increase of $18.9 \%$. In NF, the increase for SSP2-4.5 was larger than for SSP5-8.5, while it was vice-versa in FF.

\subsection{3 estimation of future runoff considering AWW}

The estimated runoffs considering the future AWWs for different SSPs are shown in Figure 8. The annual average flow showed a decrease with an increase in AWW. For SSP2-4.5, the flow in NF showed a decrease by an average of 4.0\%. The decrease was the highest in summer (6.7\%). KIOST-ESM showed the largest decrease in the average runoff by $4.7 \%$, with a decrease of $9.5 \%$ in summer, while IPSL-CM6A-LR showed the lowest decrease of $3.0 \%$. In FF, the runoff was projected to decrease by an average of $4.3 \%$, with the largest decrease in summer by $7.1 \%$. On the other hand, MIROC6 showed the largest decrease of $5.2 \%$, and KIOST-ESM showed the highest decrease of $9.6 \%$ in summer.

The annual average runoff for SSP5-8.5 was projected to decrease like SSP2-4.5. SSP5-8.5 also showed a significant decrease in summer flow. During NF, the runoff was projected to decrease by $3.9 \%$ on average, with the largest decrease of $6.5 \%$ in summer. ACCESS ESM $1-5$ showed the largest decrease of $4.9 \%$, and KIOST-ESM showed the largest decrease in summer by $8.5 \%$. In FF, the runoff was projected to decrease by $5.2 \%$, with a decrease of $8.0 \%$ in summer. CanESM5 showed the largest decrease of $13.9 \%$, with a decrease of $18.0 \%$ in summer.

\subsection{Calculation of the standardized runoff index}

\subsubsection{Comparative analysis of historical and future droughts}

The annual average number of droughts days for different durations during the historical period are shown in Figure 9. The annual average number of drought days differs by duration for the reference period. The severe drought (SRI <-1.5) increases at a high rate with the increase in duration. The period of moderate drought decreased from 62.1 days for 270 days duration drought to 58.0 days for 90 days duration drought, while that for severe drought increased from 13.0 days to 28.3 days. It was also found that more severe droughts occurred as the duration increased.

The annual average numbers of drought days in the future with and without AWW for SSP2-4.5 and SSP5-8.5 are shown in Figure 10. For SSP2-4.5, the number of drought days decreased from 60.7 days to 58.5 days on average, as the duration increased from 90 to 210 days. IPSL-CM6A-LR showed the largest decrease by 8.9 days, while MPI-ESM1-2-LR showed the smallest decrease by 2.2 days. On the other hand, several GCMs showed an increase in drought days. INM-CM4-8 showed the largest increase by 10.4 days. In addition, the rate of severe drought occurrence decreases as the duration increases. INM-CM4-8 showed the largest decrease by $6.7 \%$, while INM-CM5-0 showed the smallest by $0.7 \%$. KIOST-ESM showed the highest increase in the severe drought by $3.1 \%$ (as the duration increased from 90 to 210 days).

The characteristics of drought occurrence were different considering AWW. The number of drought days was projected to decrease by 2.8 days to 2.2 days, while the severe drought was projected to decrease by $0.7-0.5 \%$. It means the drought period increased as the duration increased when AWW was considered. The rate of occurrence for severe drought also increased.

For SSP5-8.5, the average number of drought days decreased from 62.5 to 57.3 days as the duration increased from 90 to 210 days. The drought periods was projected to decrease by all GCM. NorESM2-MM showed the largest decrease by 8.8 days. The occurrence of severe drought decreased from an average of $39.8-37.4 \%$. INM-CM4-8 showed the largest decrease by $14.3 \%$, while MRI-ESM2-0 the largest increase by $7.3 \%$. When the AWW was considered, the number of drought days decreased from 5.2 to 4.8 days, and the severe drought rate decreased from $2.5-2.3 \%$. It means the drought period increased as the duration increased, and the rate of occurrence for severe drought also increased when AWW was considered. For SSP 5-8.5, the number of drought days decreased for all GCMs when AWW was considered. The highest decrease was projected by ACCESS ESM 1-5 from 90 to 2.8 days.

All GCMs projected an increase in severe drought (-1.5 or less) period compared to the historical period. The study showed that though the drought period would decrease in the future, severe drought frequency may increase. For all durations, future droughts would have a higher rate of occurrence for severe droughts. In addition, droughts will occur more frequently and severely in the future when AWW is considered. 


\subsubsection{Comparative analysis of drought according to two future periods}

A comparative analysis of drought for two divided future periods was also performed. The future annual average numbers of drought days in SSP2-4.5 and SSP5-8.5 are shown in Figures 11 and 12, respectively.

For SSP2-4.5, the droughts were projected to occur more frequently in NF than in FF. However, the severe drought frequency was projected to be higher in NF than in FF. The differences became more significant as the duration increased. The number of drought days in NF was projected to decrease in the FF by an average of 8.5 days without AWW and 8.6 days with AWW. CanESM5 showed the largest decreased drought period (33.5 days) from NF to FF without AWW. In contrast, IPSL-CM6A-LR projected the largest increase by 25.0 days. The drought period used INM-CM5-0 showed an increase by 1.4 days with AWW, but it decreased by 1.7 days using MIROC6. The severe drought was projected to decrease by an average of $0.5 \%$. The decrease was projected by $0.8 \%$ when AWW was considered. MPI-ESM1-2-HR showed the largest decrease in severe drought period by $12.3 \%$, and INM-CM5-0 the largest increase by $8.4 \%$. When the difference in drought occurrence between with and without AWW was considered, MIROC6 showed the highest increase by $1.4 \%$, and INM-CM5-0 the highest decrease by $2.0 \%$.

For SSP5-8.5, drought days were projected to decrease by an average of 19.1 days. The decrease was projected by up to 21.1 days when AWW was considered. All GCMs showed a decrease in the drought period. MIROC6 projected the highest decrease by 30.3 days. The difference between with and without AWW was the largest for MIROC6 in terms of increase ( 0.9 days) and CanESM5 in terms of decrease (17.8 days). The severe drought frequency was projected to decrease by an average of $3.9 \%$ without AWW and a decrease by $4.0 \%$ with AWW. Without AWW, INM-CM5-0 showed the highest decrease of $31.0 \%$, and MRI-ESM2-0 showed the highest increase of $12.5 \%$. With AWW, MIROC6 showed the highest increase of $3.1 \%$, and CanESM5 showed the highest decrease of $12.1 \%$.

Future drought characteristics were different for different GCMs. Most GCMs showed that droughts in NF would be more frequent and more severe than in FF. Drought characteristics were also different according to AWW considerations. When AWW was considered, the decrease in drought days was projected from NF to FF for SSP2-4.5 but an increase from NF to FF for SSP5-8.5. SSP2-4.5 projected a decrease in severe drought rate from NF to FF, but SSP5-8.5 showed an increase.

\subsubsection{Extreme drought index}

The minimum values of the drought index for SSP2-4.5 and SSP5-8.5 are shown in Tables 4 and 5, respectively. The results differ for different GCMs. For SSP2-4.5, the minimum drought index was projected in NF rather than FF. The drought indices with and without AWW showed a higher average decrease in drought index by 0.06 in NF than 0.05 in FF for 90-day duration drought. KIOST-ESM projected the largest difference in the minimum 90-day duration drought index with and without AWW as 0.55 in NF and 0.43 in FF.

Table 4

Minimum values of the drought index in the near and far future for SSP2-4.5

\begin{tabular}{|c|c|c|c|c|c|c|c|c|c|c|c|c|c|}
\hline \multirow{2}{*}{$\begin{array}{l}\text { Duration } \\
90\end{array}$} & \multirow{2}{*}{$\begin{array}{l}\text { GCM } \\
\text { AWW }\end{array}$} & \multicolumn{2}{|c|}{ ACCESS ESM 1-5 } & \multicolumn{2}{|c|}{ CanESM5 } & \multicolumn{2}{|c|}{ INM-CM4-8 } & \multicolumn{2}{|c|}{ INM-CM5-0 } & \multicolumn{2}{|c|}{ IPSL-CM6A-LR } & \multicolumn{2}{|c|}{ KIOST-ESM } \\
\hline & & With & without & With & without & With & without & With & without & With & without & With & without \\
\hline & Near & -2.65 & -2.65 & -3.05 & -3.04 & -2.80 & -2.80 & -2.66 & -2.65 & -2.55 & -2.53 & -3.11 & -2.56 \\
\hline & Far & -2.52 & -2.57 & -2.43 & -2.44 & -3.12 & -3.14 & -3.00 & -2.95 & -2.47 & -2.42 & -2.93 & -2.50 \\
\hline & $\mathrm{GCM}$ & \multicolumn{2}{|c|}{ MIROC6 } & \multicolumn{2}{|c|}{ MPI-ESM1-2-HR } & \multicolumn{2}{|c|}{ MPI-ESM1-2-LR } & \multicolumn{2}{|c|}{ MRI-ESM2-0 } & \multicolumn{2}{|c|}{ NorESM2-LM } & \multicolumn{2}{|c|}{ NorESM2-MM } \\
\hline & Near & -2.77 & -2.75 & -2.78 & -2.76 & -2.46 & -2.45 & -2.83 & -2.82 & -2.74 & -2.74 & -3.10 & -3.07 \\
\hline & Far & -2.57 & -2.47 & -2.56 & -2.53 & -2.62 & -2.60 & -2.32 & -2.36 & -2.78 & -2.77 & -3.04 & -3.02 \\
\hline \multirow[t]{6}{*}{180} & GCM & \multicolumn{2}{|c|}{ ACCESS ESM 1-5 } & \multicolumn{2}{|c|}{ CanESM5 } & \multicolumn{2}{|c|}{ INM-CM4-8 } & \multicolumn{2}{|c|}{ INM-CM5-0 } & \multicolumn{2}{|c|}{ IPSL-CM6A-LR } & \multicolumn{2}{|c|}{ KIOST-ESM } \\
\hline & Near & -3.06 & -3.03 & -3.24 & -3.28 & -2.45 & -2.47 & -2.66 & -2.65 & -2.15 & -2.16 & -2.54 & -2.59 \\
\hline & Far & -2.35 & -2.39 & -2.35 & -2.40 & -2.82 & -2.90 & -3.02 & -3.10 & -2.60 & -2.63 & -2.63 & -2.45 \\
\hline & GCM & \multicolumn{2}{|c|}{ MIROC6 } & \multicolumn{2}{|c|}{ MPI-ESM1-2-HR } & \multicolumn{2}{|c|}{ MPI-ESM1-2-LR } & \multicolumn{2}{|c|}{ MRI-ESM2-0 } & \multicolumn{2}{|c|}{ NorESM2-LM } & \multicolumn{2}{|c|}{ NorESM2-MM } \\
\hline & Near & -2.64 & -2.67 & -2.80 & -2.78 & -2.36 & -2.33 & -2.78 & -2.82 & -2.79 & -2.84 & -2.85 & -2.83 \\
\hline & Far & -2.70 & -2.60 & -2.17 & -2.16 & -2.88 & -2.96 & -2.23 & -2.31 & -2.24 & -2.18 & -2.96 & -3.02 \\
\hline \multirow[t]{6}{*}{270} & GCM & \multicolumn{2}{|c|}{ ACCESS ESM 1-5 } & \multicolumn{2}{|c|}{ CanESM5 } & \multicolumn{2}{|c|}{ INM-CM4-8 } & \multicolumn{2}{|c|}{ INM-CM5-0 } & \multicolumn{2}{|c|}{ IPSL-CM6A-LR } & $\mathrm{KIOS}$ & ESM \\
\hline & Near & -3.19 & -3.12 & -2.92 & -2.94 & -2.43 & -2.46 & -2.77 & -2.78 & -2.48 & -2.48 & -3.02 & -3.01 \\
\hline & Far & -2.24 & -2.21 & -2.57 & -2.57 & -2.72 & -2.77 & -3.35 & -3.48 & -2.78 & -2.76 & -2.93 & -2.79 \\
\hline & GCM & MIROC & & MPI-E & M1-2-HR & MPI-E & M1-2-LR & MRI-E & M2-0 & NorES & 12-LM & NorES & 12-MM \\
\hline & Near & -2.53 & -2.48 & -2.76 & -2.73 & -2.32 & -2.35 & -2.57 & -2.54 & -2.63 & -2.59 & -3.02 & -3.03 \\
\hline & Far & -3.27 & -3.28 & -2.20 & -2.18 & -2.84 & -2.85 & -2.21 & -2.28 & -2.25 & -2.29 & -3.27 & -3.20 \\
\hline
\end{tabular}


Table 5

Minimum values of the drought index in the near and far future for SSP5-8.5

\begin{tabular}{|c|c|c|c|c|c|c|c|c|c|c|c|c|c|}
\hline \multirow{2}{*}{$\begin{array}{l}\text { Duration } \\
90\end{array}$} & \multirow{2}{*}{$\begin{array}{l}\text { GCM } \\
\text { AWW }\end{array}$} & \multicolumn{2}{|c|}{ ACCESS ESM 1-5 } & \multicolumn{2}{|c|}{ CanESM5 } & \multicolumn{2}{|c|}{ INM-CM4-8 } & \multicolumn{2}{|c|}{ INM-CM5-0 } & \multicolumn{2}{|c|}{ IPSL-CM6A-LR } & \multicolumn{2}{|c|}{ KIOST-ESM } \\
\hline & & With & without & With & without & With & without & With & without & With & without & With & without \\
\hline & Near & -2.57 & -2.50 & -2.54 & -2.55 & -2.69 & -2.71 & -2.81 & -2.81 & -2.90 & -2.87 & -3.35 & -2.71 \\
\hline & Far & -3.86 & -2.94 & -2.53 & -2.69 & -3.04 & -3.05 & -2.96 & -2.96 & -2.67 & -2.65 & -2.93 & -2.44 \\
\hline & GCM & \multicolumn{2}{|c|}{ MIROC6 } & \multicolumn{2}{|c|}{ MPI-ESM1-2-HR } & \multicolumn{2}{|c|}{ MPI-ESM1-2-LR } & \multicolumn{2}{|c|}{ MRI-ESM2-0 } & \multicolumn{2}{|c|}{ NorESM2-LM } & \multicolumn{2}{|c|}{ NorESM2-MM } \\
\hline & Near & -2.72 & -2.71 & -2.69 & -2.69 & -2.53 & -2.52 & -2.31 & -2.33 & -2.82 & -2.80 & -2.58 & -2.58 \\
\hline & Far & -2.50 & -2.49 & -2.32 & -2.34 & -2.68 & -2.64 & -2.45 & -2.45 & -2.54 & -2.53 & -2.46 & -2.47 \\
\hline \multirow[t]{6}{*}{180} & GCM & \multicolumn{2}{|c|}{ ACCESS ESM 1-5 } & \multicolumn{2}{|c|}{ CanESM5 } & \multicolumn{2}{|c|}{ INM-CM4-8 } & \multicolumn{2}{|c|}{ INM-CM5-0 } & \multicolumn{2}{|c|}{ IPSL-CM6A-LR } & \multicolumn{2}{|c|}{ KIOST-ESM } \\
\hline & Near & -2.84 & -2.76 & -2.56 & -2.48 & -2.95 & -2.85 & -2.88 & -2.77 & -2.44 & -2.45 & -2.93 & -2.84 \\
\hline & Far & -3.10 & -3.01 & -2.06 & -2.24 & -2.71 & -2.69 & -2.04 & -2.09 & -2.37 & -2.34 & -2.86 & -2.70 \\
\hline & GCM & \multicolumn{2}{|c|}{ MIROC6 } & \multicolumn{2}{|c|}{ MPI-ESM1-2-HR } & \multicolumn{2}{|c|}{ MPI-ESM1-2-LR } & \multicolumn{2}{|c|}{ MRI-ESM2-0 } & \multicolumn{2}{|c|}{ NorESM2-LM } & \multicolumn{2}{|c|}{ NorESM2-MM } \\
\hline & Near & -2.60 & -2.66 & -3.09 & -3.13 & -2.77 & -2.75 & -2.47 & -2.55 & -2.48 & -2.52 & -2.52 & -2.57 \\
\hline & Far & -2.52 & -2.55 & -2.64 & -2.66 & -2.79 & -2.78 & -2.86 & -2.76 & -2.89 & -2.85 & -2.32 & -2.35 \\
\hline \multirow[t]{6}{*}{270} & GCM & \multicolumn{2}{|c|}{ ACCESS ESM 1-5 } & \multicolumn{2}{|c|}{ CanESM5 } & \multicolumn{2}{|c|}{ INM-CM4-8 } & \multicolumn{2}{|c|}{ INM-CM5-0 } & \multicolumn{2}{|c|}{ IPSL-CM6A-LR } & KIOST & ESM \\
\hline & Near & -3.16 & -3.08 & -2.98 & -2.81 & -3.03 & -2.87 & -3.09 & -3.01 & -2.59 & -2.60 & -3.16 & -3.12 \\
\hline & Far & -3.02 & -2.96 & -1.98 & -2.15 & -2.88 & -2.86 & -1.88 & -1.88 & -2.54 & -2.49 & -3.32 & -3.16 \\
\hline & GCM & MIROC & & MPI-E & M1-2-HR & MPI-E & M1-2-LR & MRI-E & M2-0 & NorES & M2-LM & NorES & M2-MM \\
\hline & Near & -2.78 & -2.77 & -3.24 & -3.28 & -2.78 & -2.78 & -2.75 & -2.70 & -2.59 & -2.61 & -2.39 & -2.42 \\
\hline & Far & -2.77 & -2.69 & -2.43 & -2.46 & -2.13 & -2.11 & -3.19 & -2.91 & -3.24 & -3.20 & -2.73 & -2.74 \\
\hline
\end{tabular}

Similarly, SSP5-8.5 showed a decrease in the difference in the minimum drought index as 0.07 in NF and 0.03 in FF for a 90 -day duration drought. KIOST-ESM projected the large difference in the minimum drought index as 0.64 in NF and 0.48 in FF for a 90 -day duration.

The minimum drought index was analyzed differently depending on the GCM. On average, droughts were proejcts more severe in FF than in NF and more severe when AWW was considered. The difference in the minimum drought index between NF and FF was also larger when AWW was considered.

\subsection{Uncertainty in future drought}

The uncertainty in future river flow was quantified using the REA method. Figures 13 and 14 show the REA results obtained using 12 GCMs for both SSPs. The results showed that the reliability was higher considering AWW. In particular, this difference was analyzed more clearly in FF than in NF. For SSP2-4.5, IPSLCM6A-LR showed highest REA of 0.34 with AWW, and 0.32 without AWW. For SSP5-8.5, NorESM2-LM showed the highest REA of 0.22 with AWW and 0.19 without AWW. It means reliability increased when AWW was considered in calculating future river flow. It indicates the necessity of AWW consideration for drought analysis.

Figure 15 shows the uncertainty for the future drought index obtained using $12 \mathrm{GCMs}$. The results showed an increase in reliability with an increase in drought duration. The highest REA was for the 180-day duration drought. Among GCMs, IPSL-CM6A-LR showed the highest reliability, close to 1 for all drought durations. This results also showed that the reliability in the drought index was higher when AWW was considered.

\section{Conclusion}

This study proposed a new approach to identify the future hydrological drought status considering future AWWs. The proposed method was applied in the Yeongsan River basin. The future AWWs for $12 \mathrm{GCMs}$ and two SSPs were estimated using the DBN model, and the hydrological droughts were quantified using the SRI. The future AWWs showed an increase at a higher rate for SSP5-8.5 than SSP2-4.5. The average annual precipitation was projected to increase over time, but more variable for SSP5-5.8 than SSP2-4.5. The annual average temperature was also projected to increase, but at a higher rate for SSP5-8.5 than SSP2-4.5. As a result, the annual average flow was projected to increase. However, the annual average flow showed a decrease when AWW was considered due to an increase in AWW. The decrease in the average seasonal flow due to AWW consideration occurred most in summer, which caused a change in the SRI pattern in the basin.

The drought characteristics were projected to vary for different GCM. The results showed that the drought period in the future might decrease compared to the historical, but the severe drought period would increase. In other words, future droughts are expected to be more severe than the present. The drought would be more frequent and severe in NF than in FF. Future droughts showed different characteristics when AWW was considered, an increase in severity with the increase in AWW. The results indicate that the increased PET under SSPs is the major cause of increasing drought frequency and severity. The reliability for future drought was higher when AWW was considered. Besides, the drought reliability in FF was higher than in NF. The results confirm the requirement of considering AWW for the future hydrologic drought analysis to increase reliability in drought projections. 
Hydrological drought analyses are important for water resource planning and management in various sectors, including agriculture and industry. In the future, a more grounded drought analysis can be conducted considering the water balance of the region and more newly released GCMs of CMIP6.

\section{Declarations}

\section{Author Contributions}

Conceptualization, Eun-Sung Chung and Jang Hyun Sung;

Formal analysis, JinHyuck Kim, and Jang Hyung Sung;

Methodology, Eun-Sung Chung, and Shamsuddin Shahid

Writing - original draft, JinHyuck Kim and Eun-Sung Chung; and

Writing - review \& editing, Eun-Sung Chung, and Shamsuddin Shahid

\section{Ethical approval}

This article does not contain any studies with human or animal participants performed by any of the authors.

\section{Consent to Participate}

The authors declare that they have consent to participate in this paper.

\section{Consent to Publish}

The authors declare that they have consent to publish in this journal.

\section{Conflicts of interests}

The authors declare that they have no known competing interests that authors must disclose all affiliations, funding sources, financial or personal relationship:

\section{Acknowledgement}

This study was supported by the National Research Foundation of Korea (2021R1A2C20056990). It was also supported by the Korea Agency for Infrastructure Technology Advancement grant (21CTAP-C163540-01), funded by the Ministry of Land, Infrastructure and Transport.

\section{Availability of data and material}

The data can be supported if requested.

\section{References}

1. Abbaspour, K. C., Yang, J., Maximov, I., Siber, R., Bogner, K., Mieleitner, J., Zobrist, J., Srinivasan, R., 2007. Modelling hydrology and water quality in the prealpine/alpine Thur watershed using SWAT. Journal of hydrology. 333(2-4), 413-430.

2. Abbaspour, K, C., Rouholahnejad, E., Vaghefi, S., Srinivasan, R., Yang, H., Klove, B, A., 2015. Continental-scale hydrology and water quality model for Europe: calibration and uncertainty of a high-resolution large-scale SWAT model. J Hydrol 524:733-752.

3. Andersson, J. C. M., Zehnder, A. J., Jewitt, G. P., Yang, H., 2009. Water availability, demand and reliability of in situ water harvesting in smallholder rain-fed agriculture in the Thukela River Basin, South Africa. Hydrology and Earth System Sciences. 13(12), 2329-2347.

4. Arnold, J. G., Srinivasan, R., Muttiah, R. S., Williams, J. R., 1998. Large area hydrologic modeling and assessment part I: model development 1. JAWRA Journal of the American Water Resources Association. 34(1), 73-89.

5. Beran, M., \& Rodier, J. A., 1985. Hydrological aspects of drought. Studies and reports in hydrology 39. 149

6. Daloğlu, I., Nassauer, J. I., Riolo, R., Scavia, D., 2014. An integrated social and ecological modeling framework-Impacts of agricultural conservation practices on water quality. Ecology and Society. 19(3), 12.

7. Das, J., \& Umamahesh, N, V., 2018. Assessment of uncertainty in estimating future flood return levels under climate change. Natural Hazards, 93(1), 109124.

8. Dosio, A., \& Paruolo, P., 2011. Bias correction of the ENSEMBLES high-resolution climate change projections for use by impact models: Evaluation on the present climate. Journal of Geophysical Research: Atmospheres. 116, 1-22.

9. Gassman, P. W., Reyes, M. R., Green, C. H., Arnold, J. G., 2007. The soil and water assessment tool: historical development, applications, and future research directions. Transactions of the ASABE. 50(4), 1211-1250.

10. Ghosh, S., \& Mujumdar, P. P. 2009. Climate change impact assessment: Uncertainty modeling with imprecise probability. Journal of Geophysical Research: Atmospheres, 114(D18).

11. Giorgi, F., \& Mearns, L. O. 2003. Probability of regional climate change based on the Reliability Ensemble Averaging (REA) method. Geophysical research letters, 30(12). 
12. Gudmundsson, L., Bremnes, J. B., Haugen, J. E., Engen-Skaugen, T., 2012. Downscaling RCM precipitation to the station scale using statistical transformations-a comparison of methods. Hydrology and Earth System Sciences. 16(9), 3383-3390.

13. Heim Jr, R. R., 2002. A review of twentieth-century drought indices used in the United States. Bulletin of the American Meteorological Society. 83(8), 11491166.

14. Höllermann, B., \& Evers, M. 2017. Perception and handling of uncertainties in water management-A study of practitioners' and scientists' perspectives on uncertainty in their daily decision-making. Environmental Science \& Policy, 71, 9-18.

15. Javadinejad, S., Dara, R., Jafary, F., 2021. Analysis and prioritization the effective factors on increasing farmers resilience under climate change and drought. Agricultural research. 10(3), 497-513.

16. Jehanzaib, M., Shah, S. A., Yoo, J., Kim, T. W., 2020. Investigating the impacts of climate change and human activities on hydrological drought using nonstationary approaches. Journal of Hydrology. 588, 125052.

17. Jiang, S., Wang, M., Ren, L., Xu, C. Y., Yuan, F., Liu, Y., Lu, Y., Shen, H., 2019. A framework for quantifying the impacts of climate change and human activities on hydrological drought in a semiarid basin of Northern China. Hydrological Processes. 33(7), 1075-1088.

18. Jiao, D., Wang, D., Lv, H., 2020. Effects of human activities on hydrological drought patterns in the Yangtze River Basin, China. Natural Hazards. 104(1), 1111-1124.

19. Kebede, A., Raju, U. J. P., Korecha, D., Nigussie, M., 2020. Developing new drought indices with and without climate signal information over the Upper Blue Nile. Modeling Earth Systems and Environment. 6(1), 151-161.

20. Kim, J. H., Sung, J. H., Chung, E. S., Kim, S. U., Son, M., Shiru, M. S., 2021. Comparison of Projection in Meteorological and Hydrological Droughts in the Cheongmicheon Watershed for RCP4. 5 and SSP2-4.5. Sustainability. 13(4), 2066.

21. Konapala, G., \& Mishra, A. 2020., Quantifying climate and catchment control on hydrological drought in the continental United States. Water Resources Research. 56(1), e2018WR024620

22. Kwon, H. H., Lall, U., Kim, S. J., 2016. The unusual 2013-2015 drought in South Korea in the context of a multicentury precipitation record: Inferences from a nonstationary, multivariate, Bayesian copula model. Geophysical Research Letters. 43(16), 8534-8544.

23. Li, L., She, D., Zheng, H., Lin, P., Yang, Z. L., 2020. Elucidating diverse drought characteristics from two meteorological drought indices (SPI and SPEI) in China. Journal of Hydrometeorology. 21(7), 1513-1530.

24. Lin, H., Wang, J., Li, F., Xie, Y., Jiang, C., Sun, L., 2020. Drought Trends and the Extreme Drought Frequency and Characteristics under Climate Change Based on SPI and HI in the Upper and Middle Reaches of the Huai River Basin, China. Water. 12(4), 1100.

25. Li, S., Xiong, L., Dong, L., Zhang, J., 2013. Effects of the Three Gorges Reservoir on the hydrological droughts at the downstream Yichang station during 2003-2011. Hydrological Processes. 27(26), 3981-3993.

26. McKee, T. B., Doesken, N. J., Kleist, J., 1993. The relationship of drought frequency and duration to time scales. In Proceedings of the 8th Conference on Applied Climatology. 17(22), 179-183.

27. Mdemu, M., Kissoly, L., Bjornlund, H., Kimaro, E., Christen, E. W., van Rooyen, A., Struzaker, R., Ramshaw, P., 2020. The role of soil water monitoring tools and agricultural innovation platforms in improving food security and income of farmers in smallholder irrigation schemes in Tanzania. International Journal of Water Resources Development. 36(sup1), S148-S170.

28. Mishra, A. K., \& Singh, V. P., 2010. A review of drought concepts. Journal of hydrology. 391(1-2), 202-216.

29. Mondal, S. K., Huang, J., Wang, Y., Su, B., Zhai, J., Tao, H., Wang, G., Fischer, T., Wen, S., Jiang, T., 2021. Doubling of the population exposed to drought over South Asia: CMIP6 multi-model-based analysis. Science of The Total Environment. 771, 145186.

30. Naderi, M. M., Mirchi, A., Bavani, A. R. M., Goharian, E., Madani, K. 2021., System dynamics simulation of regional water supply and demand using a foodenergy-water nexus approach: application to Qazvin Plain, Iran. Journal of Environmental Management. 280, 111843.

31. Najafi, R., \& Kermani, M. R. H. 2017. Uncertainty modeling of statistical downscaling to assess climate change impacts on temperature and precipitation. Water resources management, 31(6), 1843-1858.

32. O'Neill, B. C., Tebaldi, C., Vuuren, D. P. V., Eyring, V., Friedlingstein, P., Hurtt, G., Knutti, R., Kriegler, E., Lamarque, J-F., Lowe, J., Meehl, G. A., Moss, R., Riahi, K., Sanderson, B. M., 2016. The scenario model intercomparison project (ScenarioMIP) for CMIP6. Geoscientific Model Development. 9(9), $3461-3482$.

33. Pratihar, R., Bhowmick, R., Ray, B., Sadhukhan, D., Mullik, A., Deb Majumder, B., 2020. Smart Agriculture Monitoring and Irrigation System Using IoT. Proceedings of Industry Interactive Innovations in Science. I3SET2K19.

34. Saddique, Q., Li Liu, D., Wang, B., Feng, P., He, J., Ajaz, A., Ji, J., Xu, J., Zhang, C., Cai, H., 2020. Modelling future climate change impacts on winter wheat yield and water use: A case study in Guanzhong Plain, northwestern China. European Journal of Agronomy. 119, 126113.

35. Schuol, J., \& Abbaspour, K. C., 2006. Calibration and uncertainty issues of a hydrological model (SWAT) applied to West Africa. Advances in geosciences. 9, 137-143.

36. Shackley, S., Young, P., Parkinson, S., \& Wynne, B. 1998. Uncertainty, complexity and concepts of good science in climate change modelling: are GCMs the best tools?. Climatic change, 38(2), 159-205.

37. Shrestha, A., Rahaman, M. M., Kalra, A., Jogineedi, R., Maheshwari, P., 2020. Climatological drought forecasting using bias corrected CMIP6 climate data: A case study for India. Forecasting. 2(2), 59-84.

38. Shukla, S., \& Wood, A. W., 2008. Use of a standardized runoff index for characterizing hydrologic drought. Geophysical research letters. 35(2). L02405

39. Song, Y. H., Chung, E. S., Shiru, M. S., 2020. Uncertainty Analysis of Monthly Precipitation in GCMs Using Multiple Bias Correction Methods under Different RCPs. Sustainability. 12(18), 7508. 
40. Song, Y. H., Chung, E. S., Shahid, S., 2021. Spatiotemporal differences and uncertainties in projections of precipitation and temperature in South Korea from CMIP6 and CMIP5 general circulation models. International Journal of Climatology.

41. Su, B., Huang, J., Mondal, S. K., Zhai, J., Wang, Y., Wen, S., Gao, M., LV, Y., Jiang, S., Jiang T., Li, A., 2021. Insight from CMIP6 SSP-RCP scenarios for future drought characteristics in China. Atmospheric Research. 250, 105375.

42. Sung, J. H., \& Chung, E. S., 2014. Development of streamflow drought severity-duration-frequency curves using the threshold level method. Hydrology and Earth System Sciences, 18(9), 3341-3351.

43. Sung, J. H., Ryu, Y., Chung, E. S., 2020. Estimation of Water-Use Rates Based on Hydro-Meteorological Variables Using Deep Belief Network. Water. 12(10), 2700 .

44. Sung, J. H., Kim, J., Chung, E. S., Ryu, Y., 2021. Deep-learning based projection of change in irrigation water-use under RCP 8.5. Hydrological Processes. 35(8), e14315.

45. Sutanto, S. J., \& Van Lanen, H. A., 2020. Hydrological Drought Characteristics Based on Groundwater and Runoff Across Europe. Proceedings of the International Association of Hydrological Sciences. 383, 281-290.

46. Tan, M. L., Yusop, Z., Chua, V. P., Chan, N. W., 2017. Climate change impacts under CMIP5 RCP scenarios on water resources of the Kelantan River Basin, Malaysia. Atmospheric Research. 189, 1-10.

47. Tate, E. L., and Alan Gustard., 2000. Drought definition: a hydrological perspective. Drought and drought mitigation in Europe. Springer. $23-48$.

48. Thom, H. C., 1958. A note on the gamma distribution. Monthly weather review. 86(4), 117-122.

49. Thornthwaite, C. W., 1948. An approach toward a rational classification of climate. Geographical review. 38(1), 55-94.

50. Van Loon, A. F., 2015. Hydrological drought explained. Wiley Interdisciplinary Reviews: Water. 2(4), 359-392.

51. Vasiliades, L., Loukas, A., Liberis, N., 2011. A water balance derived drought index for Pinios River Basin, Greece. Water resources management. 25(4), 1087-1101.

52. Yang, J., Reichert, P., Abbaspour, K. C., Xia, J., Yang, H., 2008. Comparing uncertainty analysis techniques for a SWAT application to the Chaohe Basin in China. Journal of Hydrology. 358(1-2), 1-23.

53. Zhai, J., Mondal, S. K., Fischer, T., Wang, Y., Su, B., Huang, J., Tao, H., Wang, G., Ullah, W., Uddin, M. J., 2020. Future drought characteristics through a multimodel ensemble from CMIP6 over South Asia. Atmospheric Research. 246, 105111.

\section{Figures}

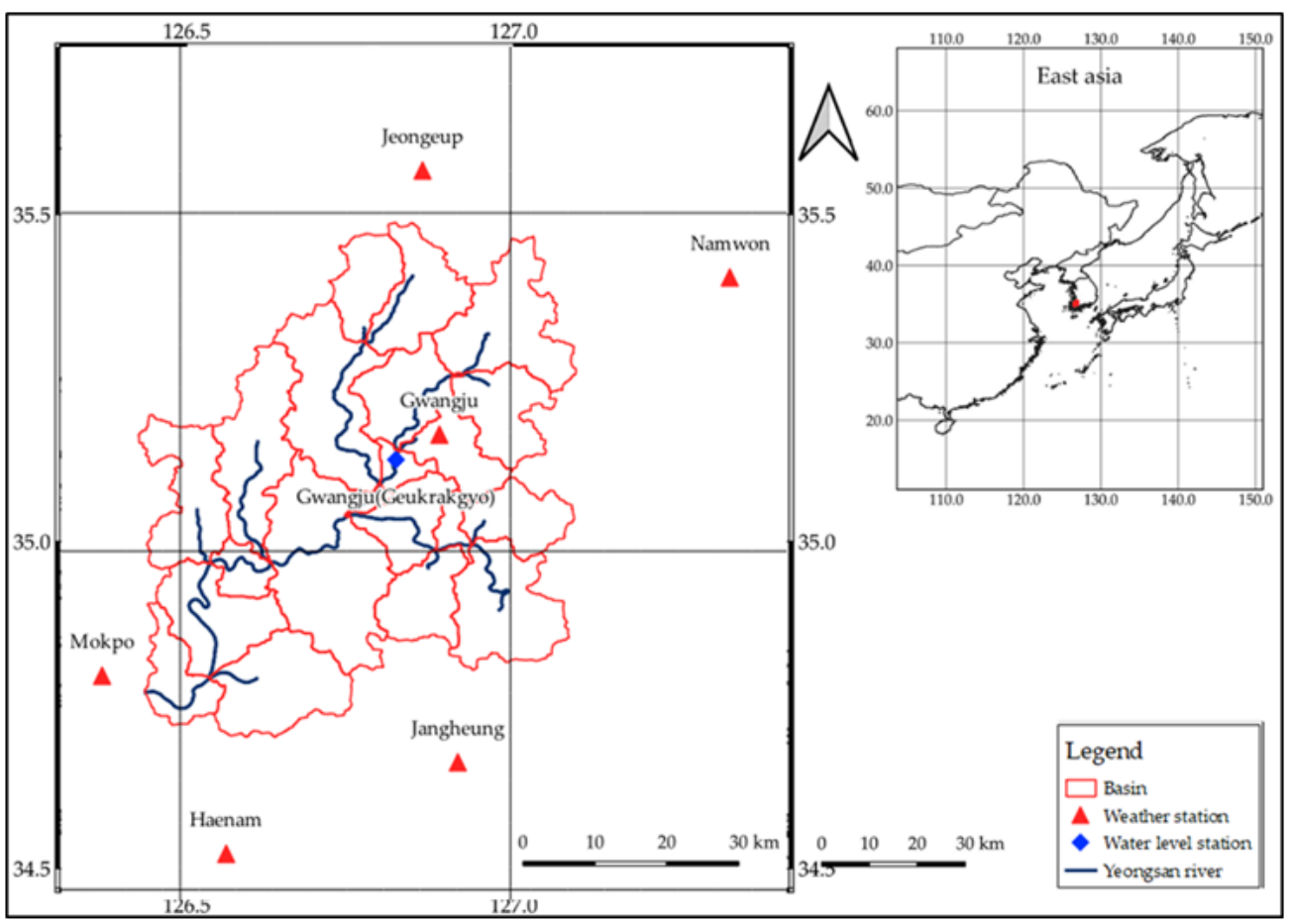

Figure 1

Description of the study area 


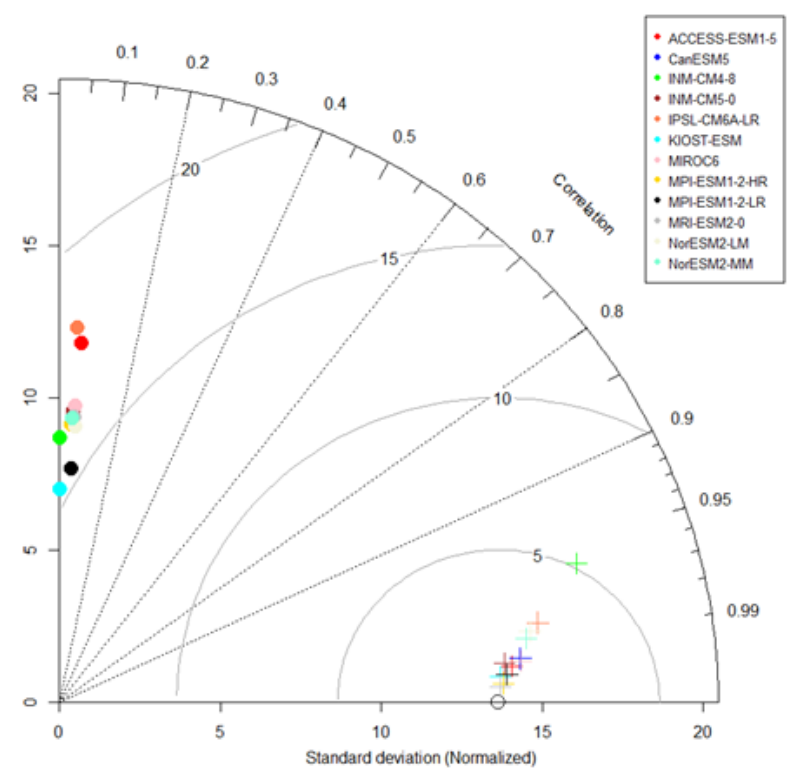

(a) Precipitation

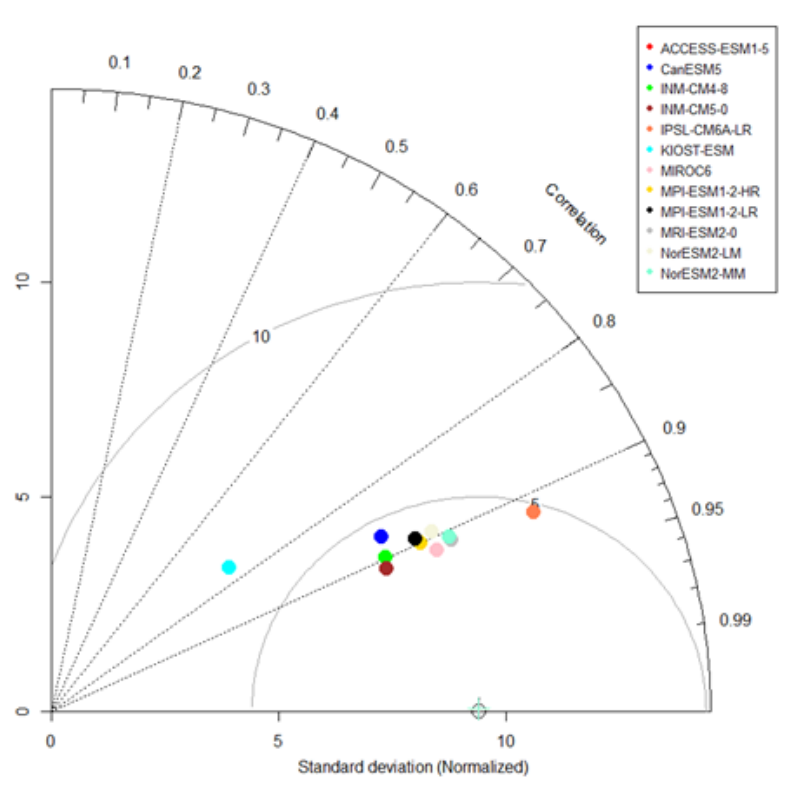

(b) Temperature

Figure 2

Taylor diagrams showing the performance of twelve GCMs after bias correction

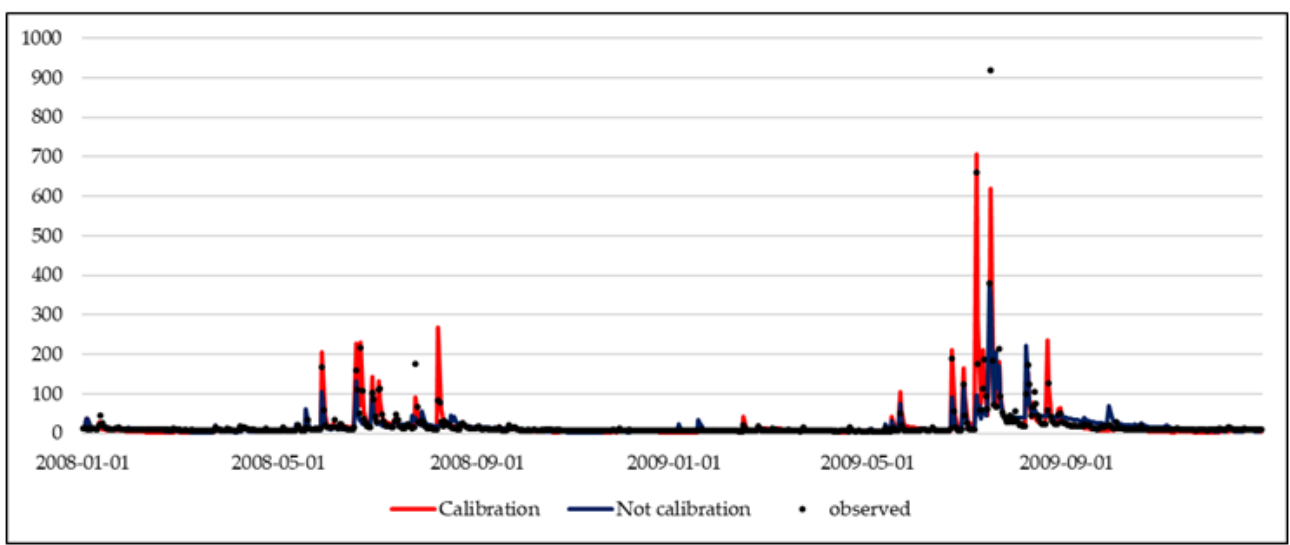

(a) Calibration (2008-2009)

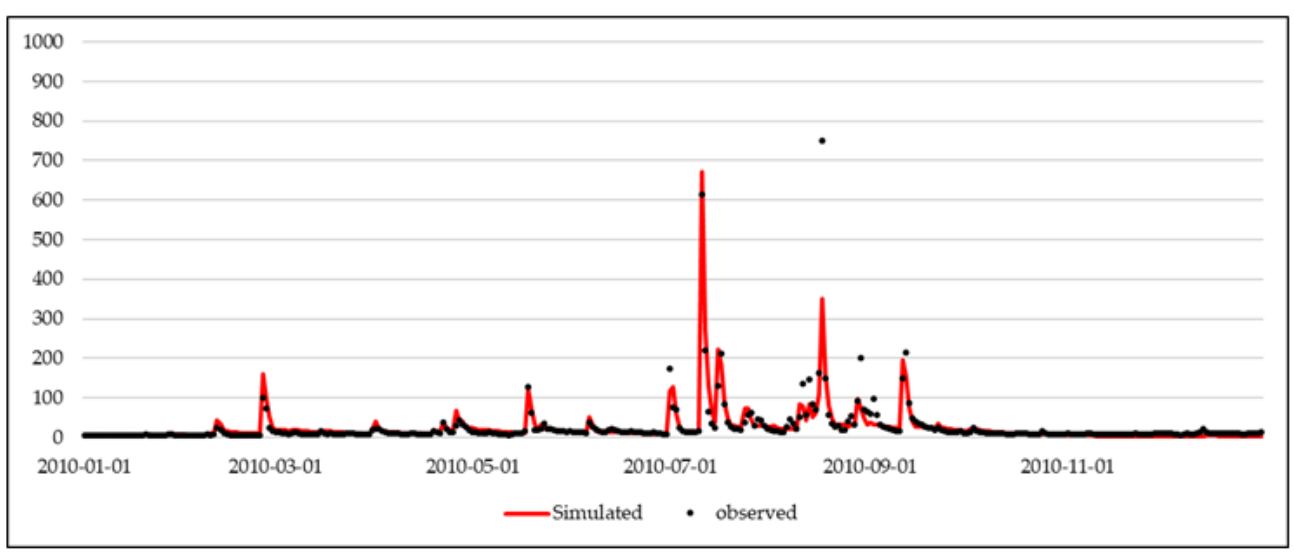

(b) Validation (2010)

Figure 3

River flow hydrographs duringmodel: (a) calibration;and (b) validation 


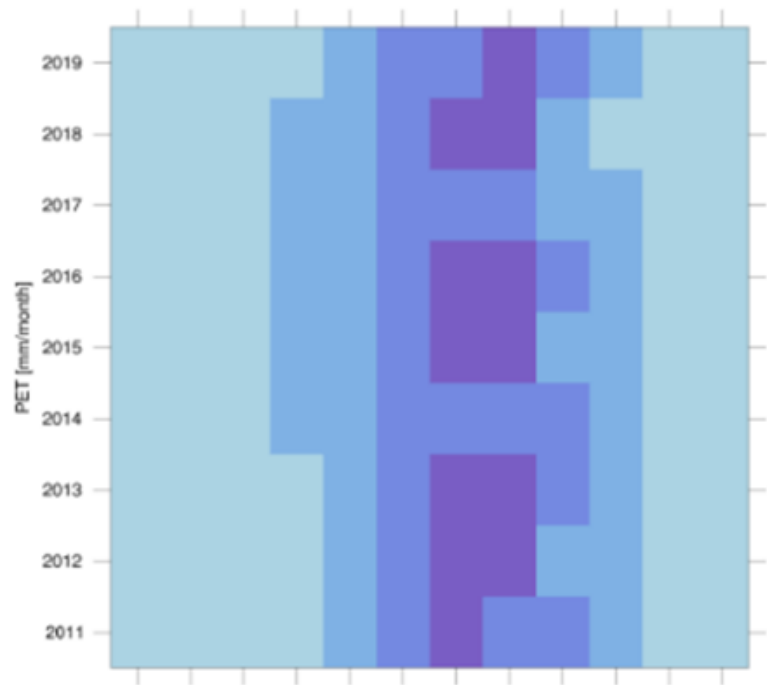

JAN FEB MAR APR MAY JUN JUL AUG SEP $\propto$ NT NOV DEC Moneh

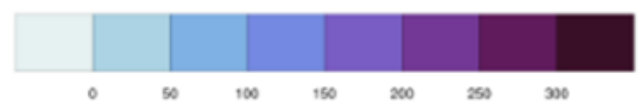

(a)

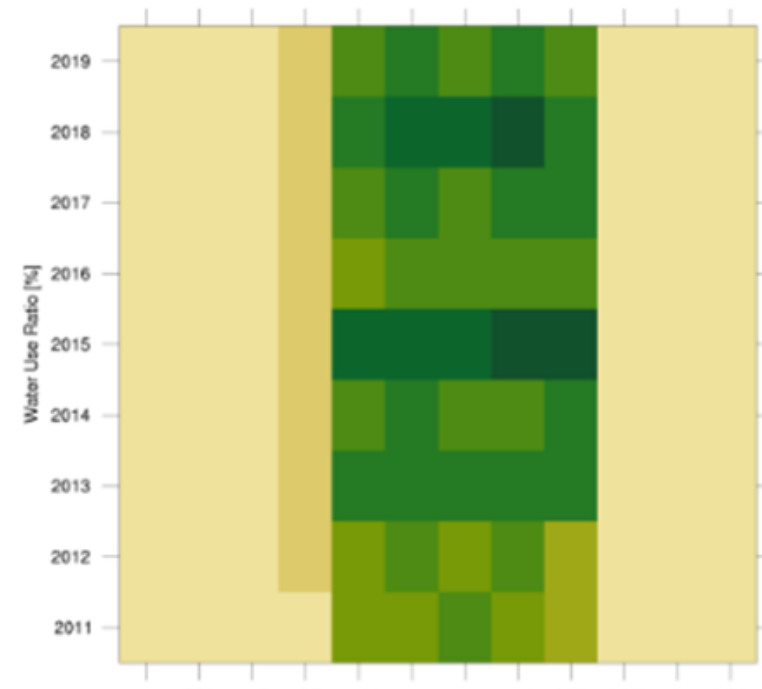

JNN FEB MAP APA MAY JUN JU AUG SEP OCT NOV DEC Month

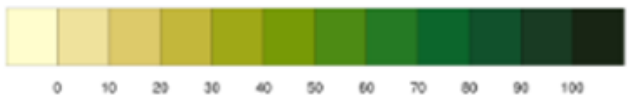

(b)

Figure 4

Matrix plots for observed monthly (a) potential evapotranspiration; and (b) the AWW rate for 2011-2019
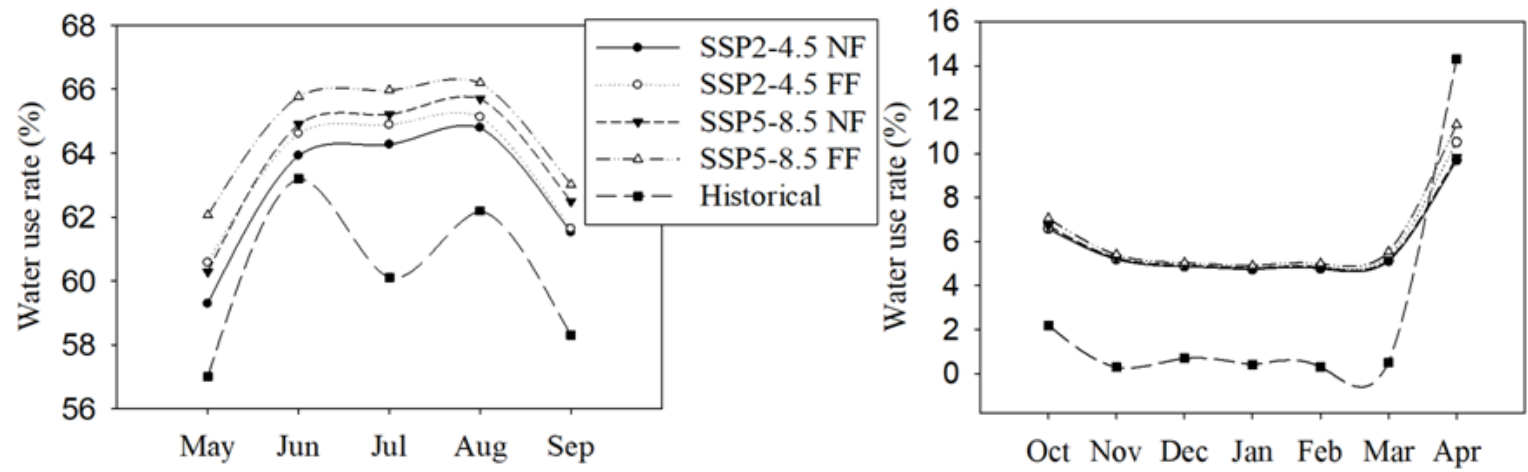

Figure 5

Variations in future AWWs in the Yeongsan riverbasin
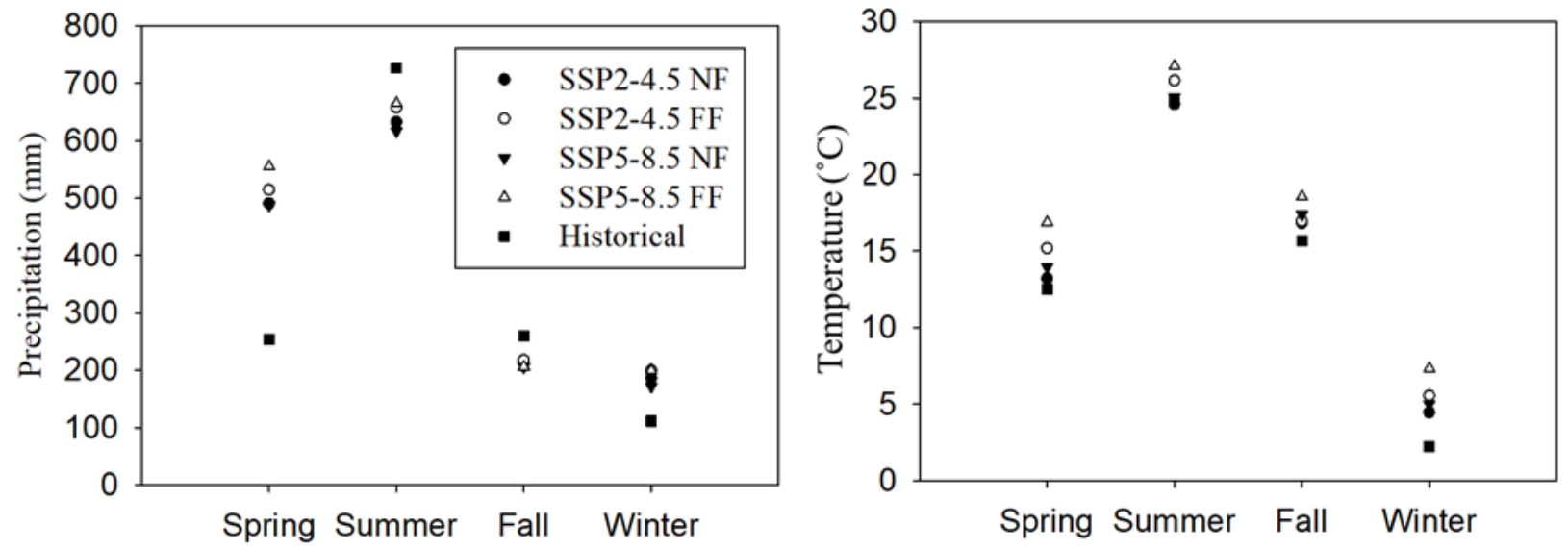

Figure 6 
Variations in precipitation and temperature in the future compared to the historical period

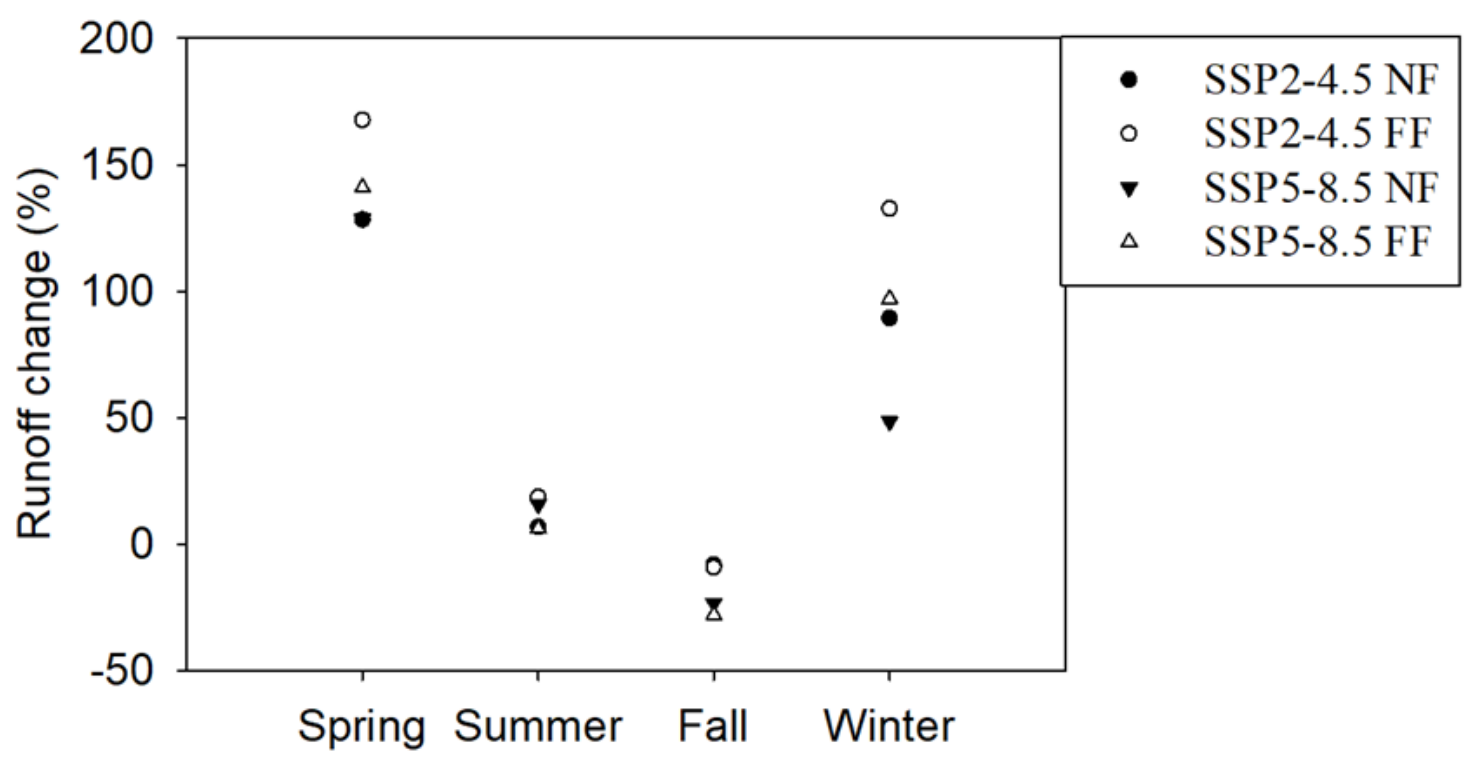

Figure 7

Flow changes in future periods compared to the base period

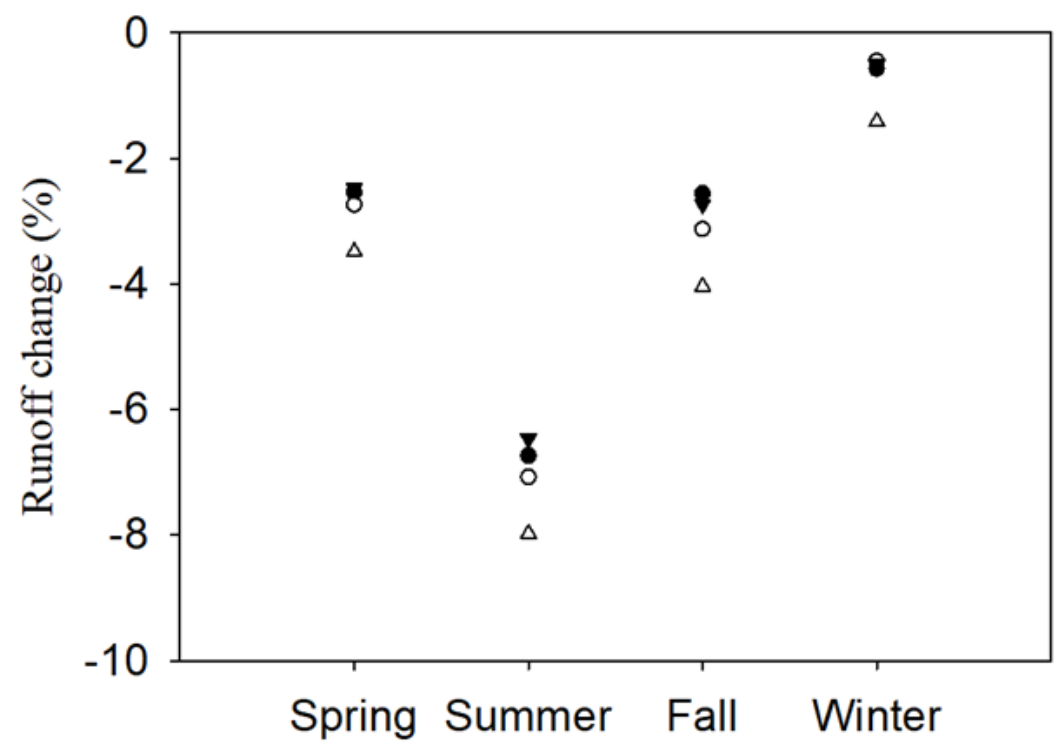

- $\quad$ SSP2-4.5 NF

- SSP2-4.5 FF

- SSP5-8.5 NF

$\triangle \quad$ SSP5-8.5 FF

Figure 8

Flow change ratios with and without considering AWW 


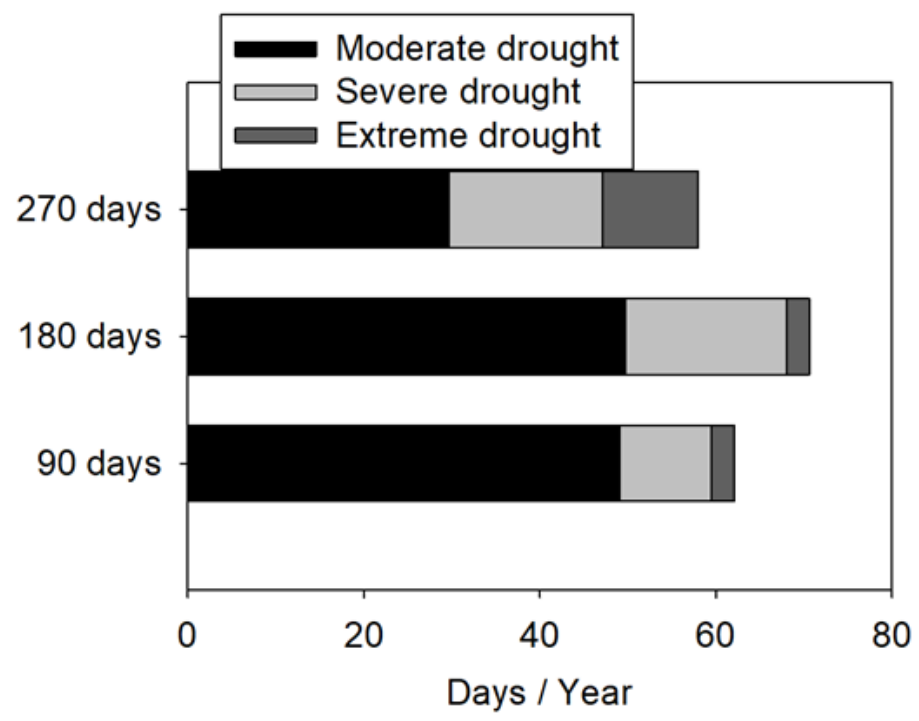

Figure 9

Annual average number of drought days in the historical period

SSP2-4.5
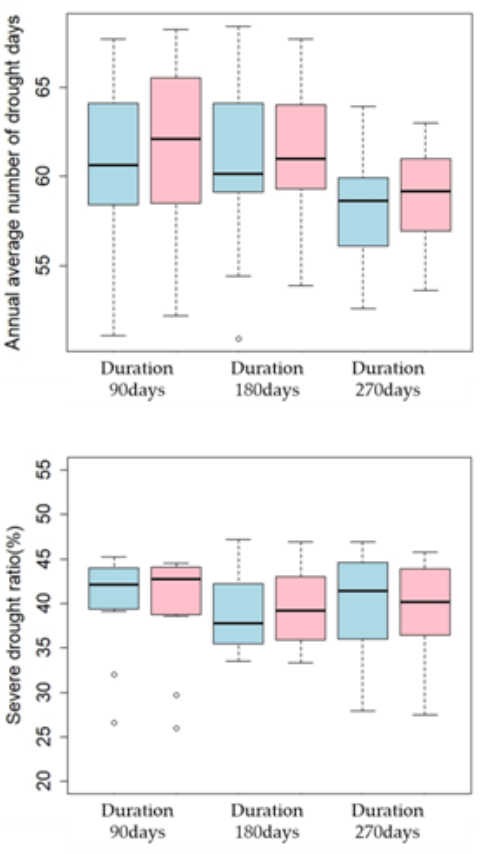

SSP5-8.5
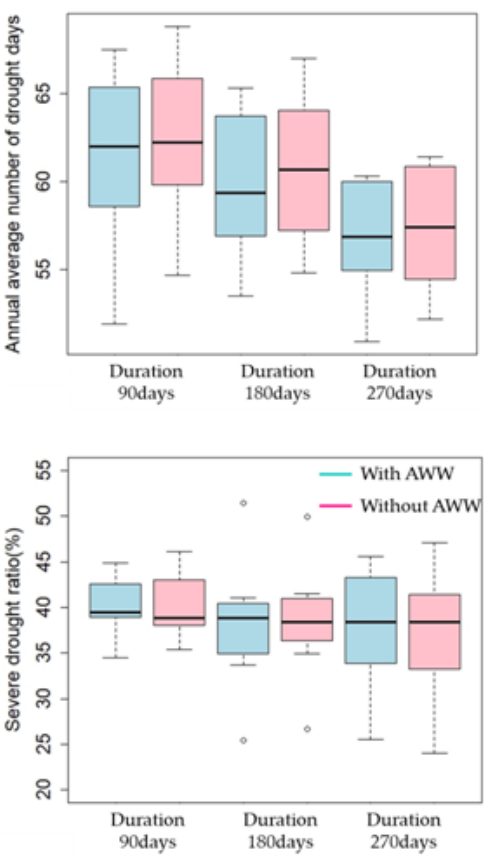

Figure 10

Future annual average number of days and severe drought ratio 
Near
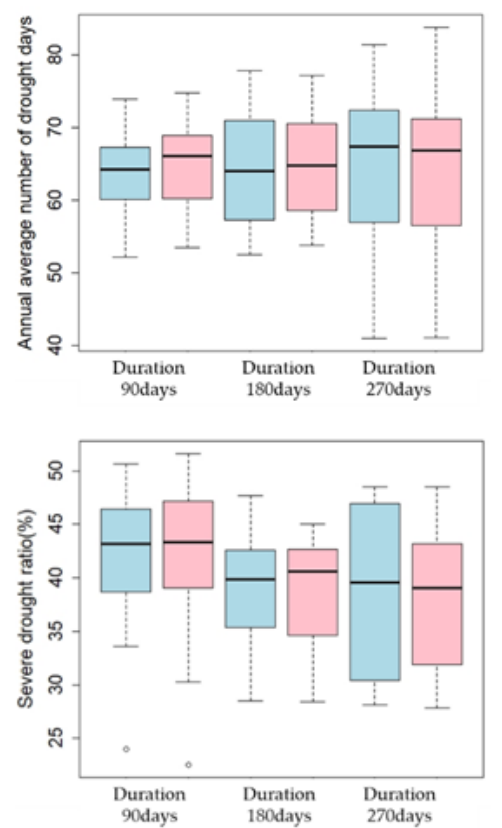

Far
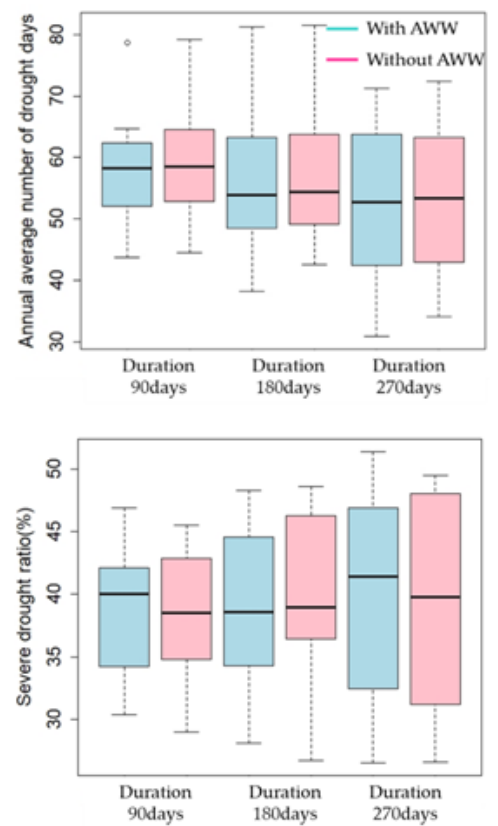

Figure 11

Future annual average number of days and severe drought ratio over time for SSP2-45
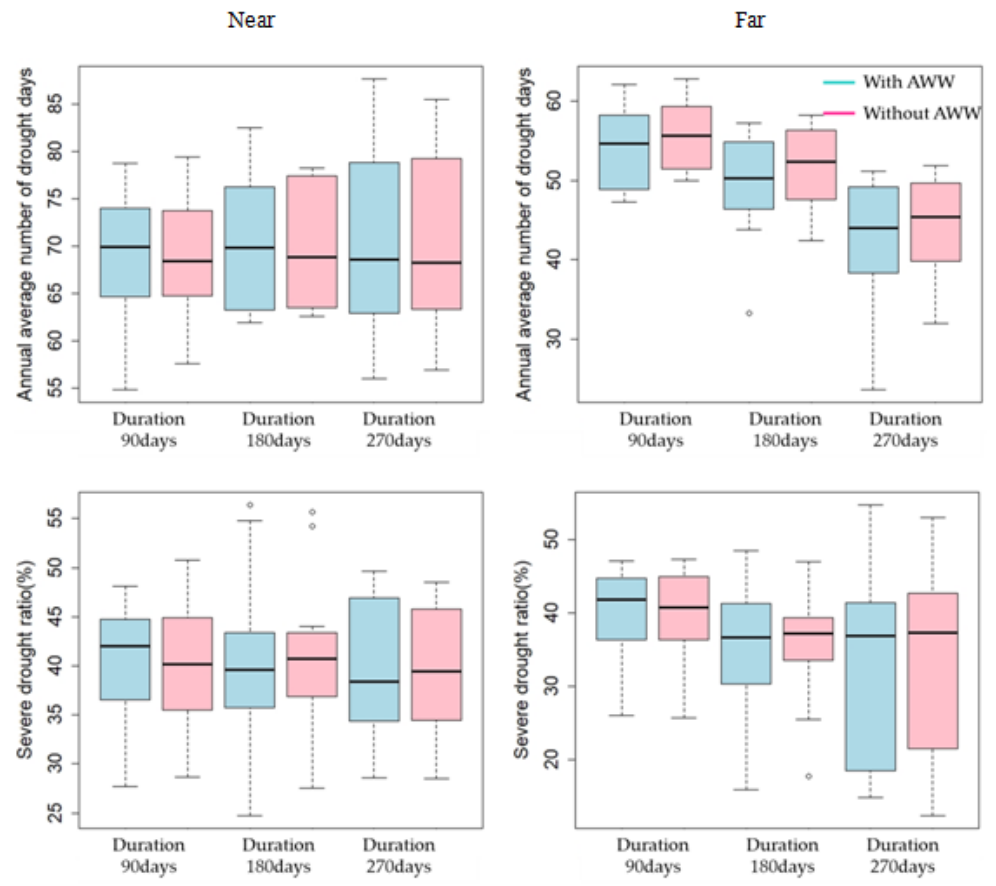

Figure 12

Future annual average number of days and severe drought ratio over time for SSP5-8.5 

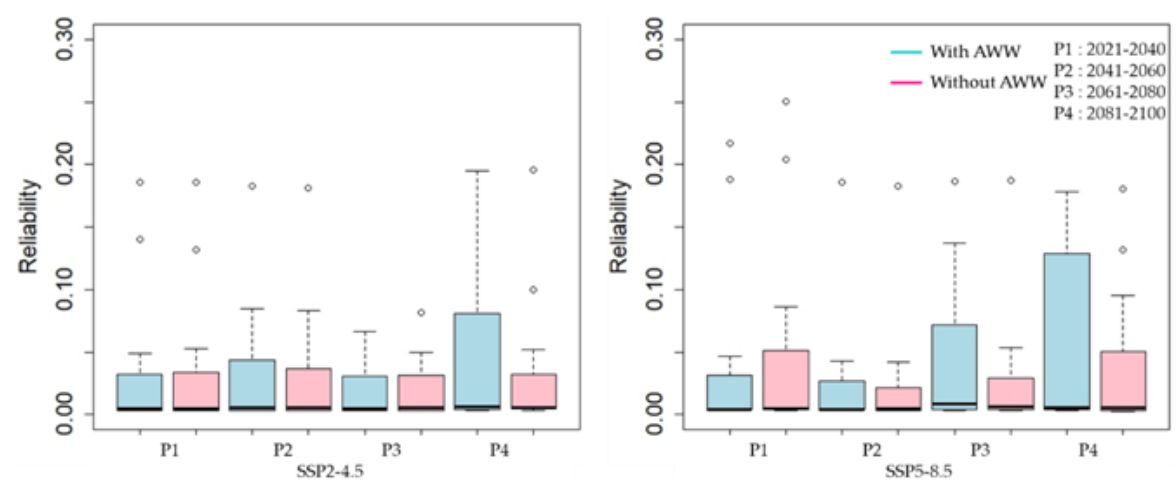

Figure 13

Uncertainty in future runoff using REA for two SSPs and fourtime frames

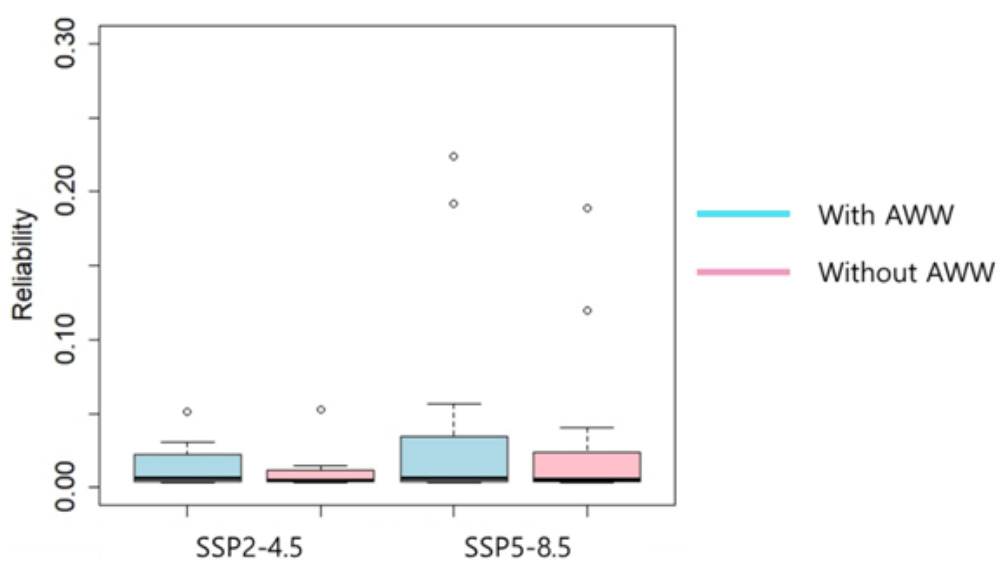

Figure 14

The average REA for two SSPs and fourtime frames 

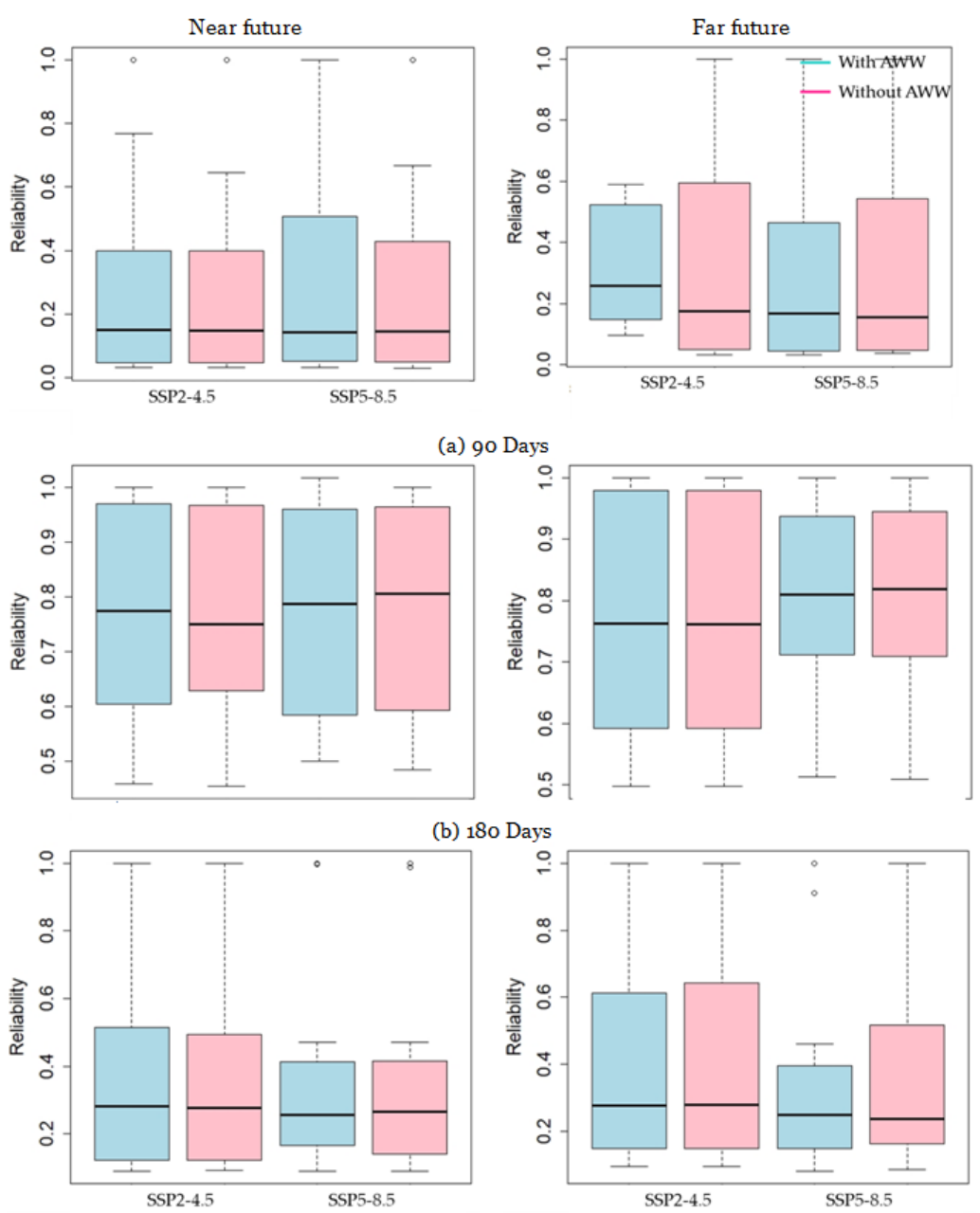

(c) 270 Days

\section{Figure 15}

Uncertainty in future drought index for two SSPs using REA 